UNIVERSIDADE DE SÃO PAULO

FACULDADE DE FILOSOFIA, CIÊNCIAS E LETRAS DE RIBEIRÃO PRETO

PROGRAMA DE PÓS-GRADUAÇÃO EM PSICOBIOLOGIA

NELLY KIM MAYURI OKUDA

\title{
ESTUDO DA RELAÇÃO ENTRE ESTILOS PARENTAIS E IMAGEM CORPORAL NO ESTADO NUTRICIONAL DE CRIANÇAS E ADOLESCENTES
}

Dissertação apresentada à Faculdade de Filosofia, Ciências e Letras de Ribeirão Preto da Universidade de São Paulo, como parte das exigências para obtenção do título de Mestre em Psicobiologia.

Ribeirão Preto 

NELLY KIM MAYURI OKUDA

Estudo da relação entre estilos parentais e imagem corporal no estado nutricional de crianças e adolescentes

\author{
Versão Corrigida \\ (Versão original encontra-se na unidade que aloja \\ o Programa de Pós-graduação)
}

Dissertação apresentada à Faculdade de Filosofia, Ciências e Letras de Ribeirão Preto da Universidade de São Paulo, como parte das exigências para obtenção do título de Mestre em Psicobiologia.

Orientador: Prof. Dr. Sebastião de Sousa Almeida

Ribeirão Preto 
Autorizo a reprodução e divulgação total ou parcial deste trabalho, por qualquer meio convencional ou eletrônico, para fins de estudo e pesquisa, desde que citada a fonte.

Catalogação na publicação

Serviço de Biblioteca e Documentação

Instituto de Psicologia da Universidade de São Paulo

Okuda, Nelly Kim Mayuri

Estudo da relação entre estilos parentais e imagem corporal no estado nutricional de crianças e adolescentes

87 p. : il. ; $30 \mathrm{~cm}$

Dissertação apresentada à Faculdade de Filosofia, Ciências e Letras de Ribeirão Preto da Universidade de São Paulo, como parte das exigências para obtenção do título de Mestre em Psicobiologia.

Versão corrigida

Orientador: Prof. Dr. Sebastião de Sousa Almeida

1. Estilos parentais. 2. Imagem corporal. 3.Obesidade infantil. 
FOLHA DE APROVAÇÃO

NELLY KIM MAYURI OKUDA

\section{ESTUDO DA RELAÇÃO ENTRE ESTILOS PARENTAIS E IMAGEM \\ CORPORAL NO ESTADO NUTRICIONAL DE CRIANÇAS E ADOLESCENTES}

Dissertação apresentada à Faculdade de Filosofia, Ciências e Letras de Ribeirão Preto da Universidade de São Paulo, como parte das exigências para obtenção do título de Mestre em Psicobiologia

Aprovado em:

Banca Examinadora

Prof.(a) Dr.(a):

Instituição:

Assinatura:

Prof.(a) Dr.(a):

Instituição:

Assinatura:

Prof.(a) Dr.(a):

Instituição:

Assinatura:

Prof.(a) Dr.(a):

Instituição:

Assinatura: 



\section{DEDICATÓRIA}

Dedico este trabalho ao meu pai o maior incentivador dos meus estudos, de quem eu sinto imensa saudade. 



\section{AGRADECIMENTOS}

Agradeço à minha mãe, minha companheira que me proporcionou realizar este sonho de estudar e me formar na USP e dar continuidade aos meus estudos na pós-graduação. Mãe, sem a sua ajuda e incentivo, eu não teria chegado até aqui.

Ao meu amor e melhor amigo Rafa, por sempre acreditar em mim, por me apoiar e me incentivar nos momentos mais difíceis. Por toda paciência e contribuição. Pelos conselhos, pela companhia e principalmente por todos os sonhos compartilhados.

Aos meus irmãos Yan, Tammy, Dayton e Aline que serviram de exemplo por toda a minha vida e que me deram o melhor presente que poderiam me dar. Meus sobrinhos! Yuri, Maria, Yanzinho, Ane, Bia, Sofia, Mario e Ana.

Ao Professor Sebastião pela oportunidade de trabalhar no Laboratório de Nutrição e comportamento, que eu tanto sonhei. Agradeço por toda contribuição no trabalho e por todos os ensinamentos.

Aos colegas do laboratório, Professora Telma, Fernanda, Renata, Raquel, Natasha, Alessandra, Gabi, Alê, Camila, Gabi Pap, Camyla, Bia, Alex e Rodrigo. Agradeço pela amizade, pelos conselhos e ajuda com o meu trabalho.

A Profa. Tania, pela amizade e carinho. Pelos cappuccinos e principalmente por todo conhecimento compartilhado.

Foi uma alegria dividir esses anos ao lado de todos vocês.

Aos professores da Banca pela disponibilidade e contribuição.

“A satisfação reside no esforço, não no resultado obtido.

O esforço total é a plena vitória."

Mahatma Gandhi 



\section{RESUMO}

OKUDA, N. K. M. Estudo da relação entre estilos parentais e imagem corporal no estado nutricional de crianças e adolescentes. 2017. 87F. Dissertação (Mestrado) Faculdade de Filosofia, Ciências e Letras de Ribeirão Preto da Universidade de São Paulo - USP, Ribeirão Preto/SP, 2017.

Mudanças nos hábitos alimentares somadas ao sedentarismo são os principais fatores do aumento da prevalência do excesso de peso. A obesidade infantil é uma realidade, tornando-se um grave problema de saúde pública mundial. Na infância, a família é considerada o principal apoio ao indivíduo interferindo diretamente no desenvolvimento dos jovens. O presente estudo teve como objetivos verificar a influência dos estilos parentais na prática de atividade física e no estado nutricional dos estudantes de três escolas do ensino fundamental; avaliar a acurácia e satisfação na percepção do tamanho corporal dos estudantes e também a percepção dos pais em relação ao tamanho corporal dos filhos. A amostra consistiu em 154 estudantes, com idade entre nove e 12 anos, de ambos os sexos e seus respectivos responsáveis, sendo um total de 308 participantes. Para classificar o estilo parental foi utilizado as Escalas de Exigência e Responsividade e a percepção da imagem corporal foi investigada por meio da Escala de Silhuetas Infantis. Para análise dos resultados foram utilizados o teste de Correlação Linear de Pearson e Análise de Variância (ANOVA). Os resultados mostraram que 40\% dos estudantes estavam acima do peso, e a prática de atividade física foi menor nos estudantes com pais menos exigentes. O estilo parental mais frequente avaliado tanto pelas crianças quanto pelos pais foi o autoritativo. Apenas $23,4 \%$ dos estudantes apresentaram uma percepção acurada do seu tamanho corporal e 50\% dos pais subestimaram o tamanho corporal de seus filhos. Essa subestimação foi maior quanto maior o índice de massa corporal da criança. Concluímos que uma pequena parcela dos estudantes tem uma percepção acurada do seu tamanho corporal, e que há uma tendência dos pais subestimarem o tamanho corporal dos filhos. Poucos estudantes foram considerados ativos fisicamente. Não encontramos relação entre o estado nutricional da criança e o estilo parental da família.

Palavra-chave: Estilos Parentais. Imagem Corporal. Obesidade Infantil. 



\begin{abstract}
Changes in eating habits coupled with physical inactivity are the main factors in increasing the prevalence of overweight. Childhood obesity is a reality, making it a serious public health problem worldwide. In childhood, the family is considered the main support to the individual directly interfering in the development of the young. The present study had as objective to verify the influence of the parental styles in the practice of physical activity and nutritional status of the students; and assess the accuracy and overall satisfaction of students and their caregivers with their body image. The sample consisted of 154 students, aged between 9 and 12 years, of both sexes and their respective responsible ones, being 308 participants. To classify the parenting style was used the Scales of Responsiveness and Demandingness and the physical activity practice of the students was evaluated by the questionnaire to evaluate the Physical Activities of children and adolescents. The perception of the corporal image was investigated through the Scale of Silhouettes for children. To analyze the results, Pearson's linear correlation and Variance Analysis were used to analyze the results. The results showed that $40 \%$ of the students are overweight. The practice of physical activity was lower in students with less demanding parents. $23.4 \%$ of students had an accurate perception of their body size and $50 \%$ of the parents underestimated the size of their children. This underestimation was greater the higher the body mass index of the child. We conclude that a small portion of the students has an accurate perception of their body size, and that parents have a distorted perception of the children's body image. There was no relationship between the child's nutritional status and the family's parental style.
\end{abstract}

Key-words: Parenting styles and Child obesity 



\section{LISTA DE FIGURAS}

FIGURA 1 - Classificação dos limites de Percentis para IMC de crianças e adolescentes de 5 a 19 anos, segundo a classificação da OMS, 2007. 38

FIGURA 2 - Classificação dos limites de IMC para adulto. OMS 2000. .38

FIGURA 3 - Classificação dos estilos parentais de acordo com a pontuação nas escalas de exigência e responsividade .39

FIGURA 4 - Acurácia da percepção da imagem corporal dos estudantes $(n=154)$, de três escolas do ensino fundamental, por estado nutricional. Ribeirão Preto/SP, 2017. 



\section{LISTAS DE TABELAS}

TABELA 1 - Caracterização descritiva dos estudantes de três escolas do ensino fundamental com idade entre 9 e 12 anos $(n=154)$. Ribeirão Preto, 2017 41

TABELA 2 - Frequências absoluta e relativa da classificação do estado nutricional segundo a classificação da OMS (2007) dos estudantes de três escolas do ensino fundamental $(n=154)$ Ribeirão Preto/SP, 2017. .42

TABELA 3 - Frequência relativa e absoluta dos estilos parentais, por casal $(n=135)$, Ribeirão Preto/SP, 2017. .43

TABELA 4 - Frequência absoluta e relativa da pratica de atividade física e horas inativa dos estudantes de três escolas do ensino fundamental $(n=154)$. Ribeirão Preto/SP, 2017. 45

TABELA 5 - Frequência relativa e absoluta da caracterização da amostra dos responsáveis pelos estudantes $(n=154)$. Ribeirão Preto/SP, 2017. .46

TABELA 6 - Média e desvio padrão das variáveis antropométricas dos estudantes e de um de dos pais ou responsável. Ribeirão Preto/SP, 2017. .55

TABELA 7 - Frequência relativa e absoluta da acurácia dos estudantes perante o seu tamanho corporal $(n=154)$ Ribeirão Preto/SP, 2017 .55

TABELA 8 - Frequência relativa e absoluta da satisfação dos estudantes com o seu tamanho corporal $(n=154)$ Ribeirão Preto/SP, 2017. .57

TABELA 9 - Frequência relativa e absoluta da diferença entre a satisfação e acurácia de meninos e meninas em relação ao seu tamanho corporal $(n=154)$. Ribeirão Preto/SP, 2017. .58

TABELA 10 - Frequência relativa e absoluta da acurácia e satisfação dos pais em relação ao tamanho corporal dos filhos $(n=154)$. Ribeirão Preto/SP, 2017. .59 



\section{LISTA DE ABREVIATURAS E SIGLAS}

CCEB Critério de Classificação Econômica Brasil

EFS Escala de Figuras de Silhuetas

EER Escalas de Exigência e de Responsividade

ERICA Estudo de Riscos Cardiovasculares em Adolescentes

IBGE Instituto Brasileiro de Geografia e Estatística

IMC Índice de Massa Corporal

OMS Organização Mundial de Saúde

POF Pesquisa de Orçamentos Familiares

VIGITEL Vigilância de fatores de risco e proteção para doenças crônicas por Inquérito Telefônico 



\section{SUMÁRIO}

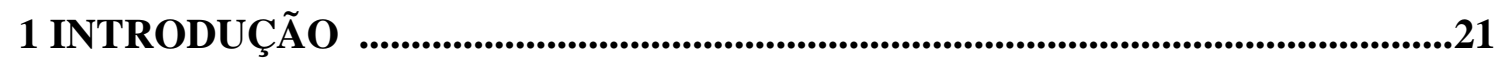

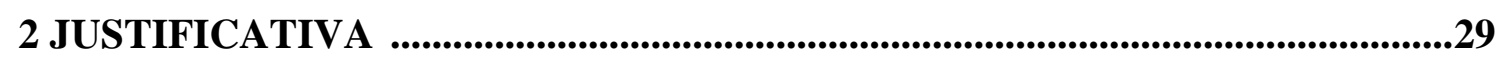

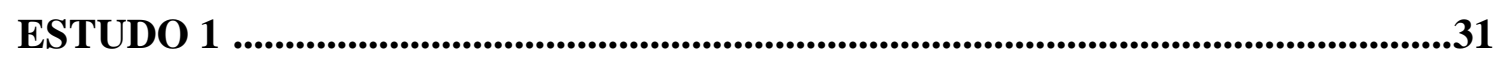

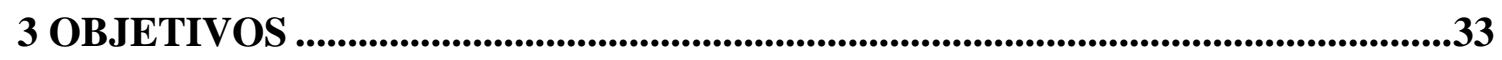

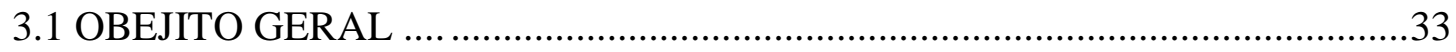

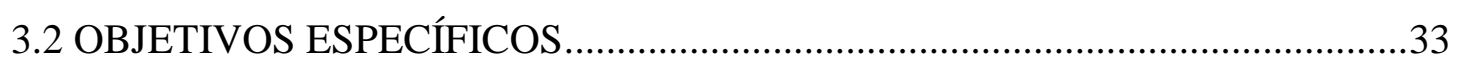

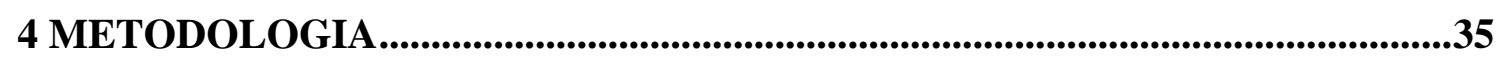

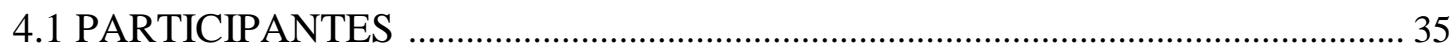

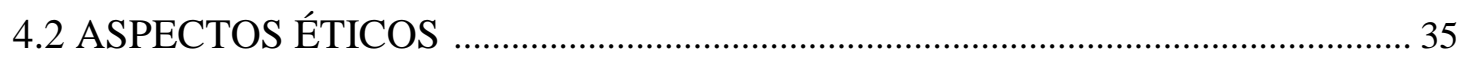

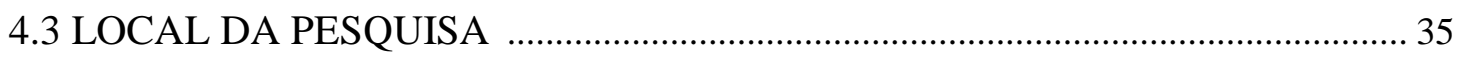

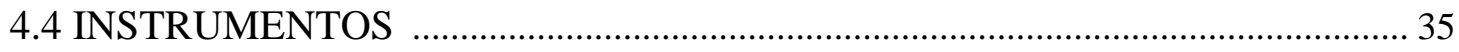

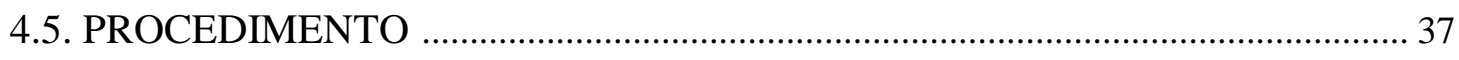

4.5.1. Coleta de dados com criança e adolescentes............................................... 37

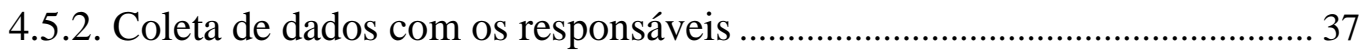

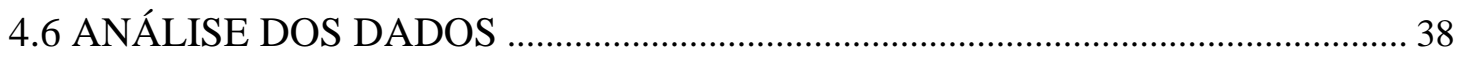

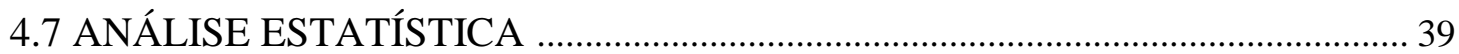

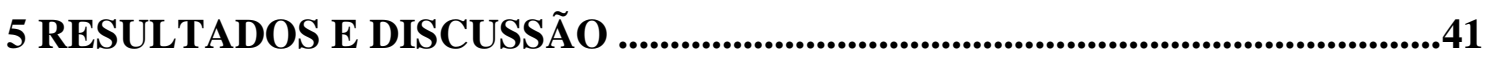

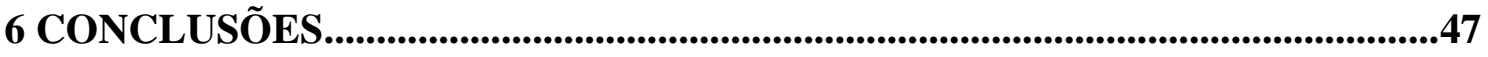

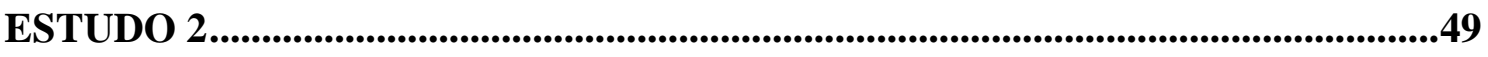

7 OBJETIVO _.............................................................................................................................51

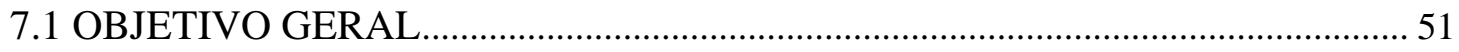

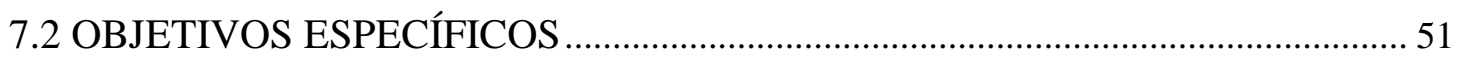

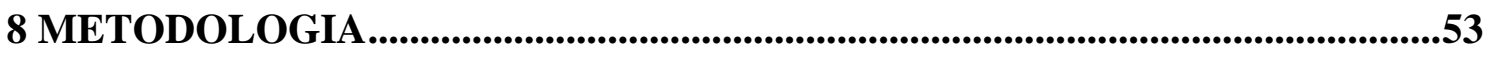

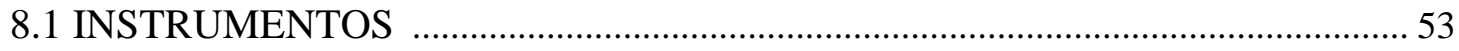

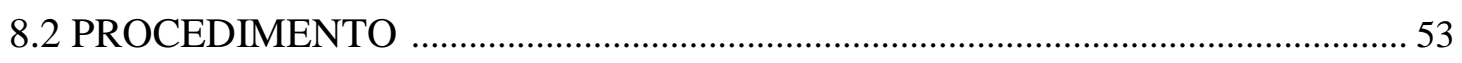

8.2.1. Coleta de dados com criança e adolescentes ................................................ 53

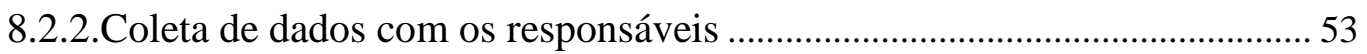




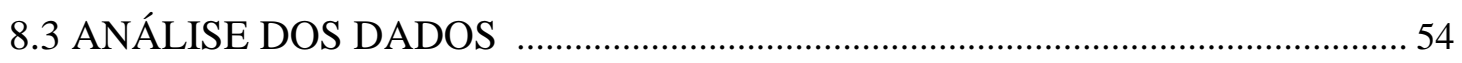

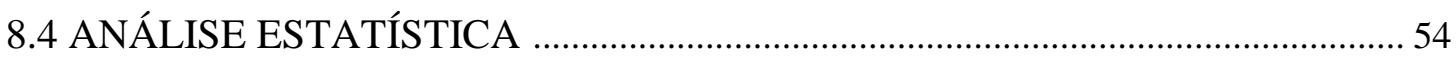

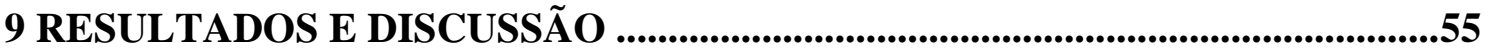

10 CONCLUSÃO

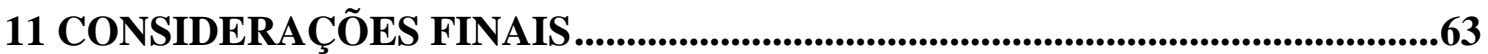

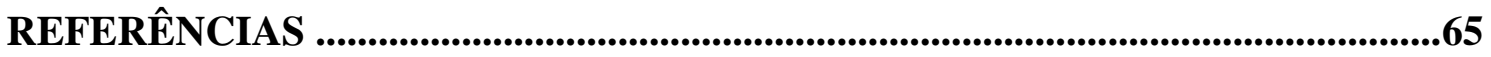

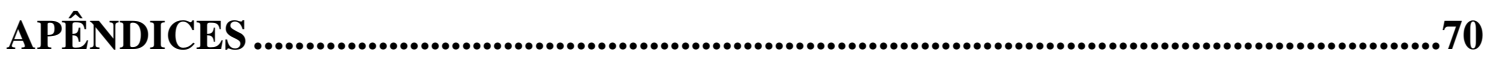

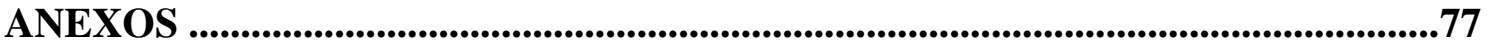




\section{INTRODUÇÃO}

\section{Transição Nutricional}

Mudanças nos hábitos alimentares vêm ocorrendo ao longo dos últimos anos. Popkin, Guo e Lopes (1993) caracterizam a transição nutricional como mudanças nos padrões nutricionais (peso, estatura e composição corporal) por meio das modificações na dieta, somadas a mudanças sociais, econômicas, demográficas e alterações no estilo de vida, provocando alterações no estado de saúde dos indivíduos.

Na comparação dos resultados da Pesquisa de Orçamentos Familiares (POF) de 2008-2009 com os da POF de 2002-2003, verificam-se mudanças nos padrões alimentares da população brasileira. Houve aumento na disponibilidade e consumo de alimentos ultraprocessados (biscoitos, refrigerantes, produtos lácteos, bebidas alcoólicas, refeições prontas e misturas industrializadas) e diminuição no consumo de alimentos integrais, in natura e minimamente processados (arroz, feijão, leite, farinha de trigo) (IBGE, 2010). Segundo o Ministério da Saúde (2016), no Brasil apenas um terço dos adultos seguem as recomendações do consumo diário de frutas.

\section{Obesidade}

A obesidade é multicausal e envolve fatores genéticos, fisiológicos, psicológicos, ambientais e sociais. Mudança nos padrões alimentares com dietas hipercalóricas e de baixa qualidade nutricional, somado ao sedentarismo cada vez mais comum no mundo moderno, são os principais fatores do aumento da prevalência da obesidade e do sobrepeso no mundo, de acordo com os dados da Organização Mundial de Saúde (OMS) (1998). O Instituto Brasileiro de Geografia e Estatística (IBGE), por meio da POF (2008-2009), divulgou a análise da evolução do estado nutricional da população adulta brasileira e mostrou que a prevalência de excesso de peso e de obesidade aumentou nas últimas décadas (IBGE, 2010).

Dados recentes, obtidos a partir da pesquisa de Vigilância de fatores de risco e proteção para doenças crônicas por Inquérito Telefônico (VIGITEL) mostraram que o excesso de peso cresceu 26,3\% em dez anos, passando de 42,6\% em 2006 para 53,8\% em 2016. Enquanto o excesso de peso aumentou mais de $20 \%$ em dez anos, a obesidade cresceu 60\% no Brasil, passando de 11,8\% em 2006 para 18,9\% em 2016. Ou seja, mais 
de $70 \%$ dos adultos brasileiros estão acima do peso, na faixa de sobrepeso e obesidade (VIGITEL, 2016).

Ainda de acordo com os dados do VIGITEL (2016), os indicadores de excesso de peso aumentam com a idade e é maior entre aqueles com menos escolaridade, o que mostra a vulnerabilidade das famílias de baixa renda no país. Juntamente com o aumento do excesso de peso da população, são crescentes também os dados referentes às doenças crônicas não transmissíveis. Cresceu em 61,8\% e 14,2\% o número de pessoas diagnosticadas com diabetes e hipertensão arterial, respectivamente.

O padrão de vida das crianças e adolescentes acompanha estas mudanças e a obesidade infantil é uma realidade, tornando-se um grave problema de saúde pública mundial. Segundo a OMS (2015) mundialmente os dados de obesidade em menores de cinco anos em 2015 foi estimado em 42 milhões de crianças. Na América Latina as taxas de sobrepeso e obesidade vêm crescendo nas últimas três décadas. Cerca de 20$25 \%$ da população total de crianças e adolescentes (0-18 anos) estão acima do peso nessa região (OMS, 2011; RIVERA et al., 2014).

No Brasil, o número de crianças com baixo peso vem diminuindo e atualmente mais de 7,3\% das crianças com menos de cinco anos apresentam excesso de peso. Entre cinco e nove anos, o percentual de crianças com excesso de peso é maior, chegando a $33 \%$. Na adolescência a prevalência é de 20,5\% (IBGE, 2010).

O que tem influenciado em maior grau esse aumento de peso nos jovens é a mudança no estilo de vida. Além das mudanças no hábito alimentar, no qual há um crescente consumo de produtos industrializados, há uma modificação na ocupação do tempo livre dos jovens (GUEDES et al., 2010). As crianças têm se ocupado cada vez mais com atividades sedentárias no seu lazer, passando mais tempo em frente à televisão, celular, jogos e computadores. O uso abusivo destes eletrônicos ocupa horas vagas em que a criança poderia estar realizando outras atividades. A Academia Americana de Pediatria recomenda que os jovens não devem ultrapassar duas horas por dia em frente à televisão (AAP, 2001).

Segundo dados do Estudo de Riscos Cardiovasculares em Adolescentes (ERICA), primeiro estudo brasileiro com representatividade nacional, que avaliou mais de 74 mil adolescentes de todas as regiões do Brasil, a prevalência de obesidade, 
sedentarismo e comportamento alimentar saudável em adolescentes, aproximadamente 73,5\% dos estudantes analisados relataram passar duas ou mais horas por dia em atividades sedentárias, como assistindo à televisão, no computador e no celular (OLIVEIRA et al., 2016).

\section{Sedentarismo}

Segundo o Ministério da Saúde, no Brasil 37,6\% dos adultos praticam 150 minutos de atividade física por semana no seu tempo livre, como recomendado pela OMS. O sedentarismo leva à obesidade, e por sua vez a obesidade faz a criança ser ainda mais sedentária (JEEB; MOORE, 1999). De acordo com a OMS (2011), o ideal é que as crianças e jovens com idade entre cinco e 17 anos pratiquem 60 minutos de atividade física moderada a intensa, diariamente, o que inclui brincadeiras, jogos, transporte, educação física, ou exercício programado.

Wright et al. (2001) afirmam que o índice de massa corporal (IMC) na infância se correlaciona positivamente com o IMC do adulto e quanto mais tempo o indivíduo se mantém obeso, maior e mais precocemente é a chance das complicações ocorrerem. Aumenta também a chance dessas crianças desenvolverem doenças crônicas como o diabetes e doenças cardiovasculares. Por esses motivos, a obesidade deve ser tratada ainda na infância (EBBELING; PAWLAK; LUDWIG, 2002).

O comportamento alimentar do pré-escolar é determinado em primeiro lugar pela família, da qual a criança é totalmente dependente, e em segundo lugar por outras interações sociais e culturais da criança. Os pais são os principais educadores nutricionais dos filhos afetando, assim, diretamente o comportamento alimentar da criança (GILLESPIE; ACTERBERG, 1989; KOIVISTO,1996). Com essa forte influência que os pais exercem sobre a ingestão alimentar nos filhos, se esses hábitos não forem modificados ou manejados em conjunto, dificilmente o tratamento terá sucesso (BIRCH, 1998). Alguns estudos indicam uma relação entre o Índice de Massa Corporal (IMC) dos filhos com o IMC de seus pais (CAMARGO et al., 2013; GIUGLIANO; CARNEIRO, 2004).

O combate à obesidade na infância é ainda mais difícil do que na fase adulta, pois está relacionado a mudanças de hábitos principalmente dos pais ou responsáveis, pois a criança ainda não tem entendimento quanto aos danos da obesidade (MELLO; 


\section{LUFT; MEYER, 2004).}

As principais dificuldades encontradas pela família durante o tratamento da obesidade infantil são as modificações da rotina alimentar da família inteira, por meio da adequação do ambiente, melhora do cardápio da família, imposição de limites e aderência ao tratamento pela criança. É importante o empenho e a contribuição de todos os familiares para superarem o problema juntos (MORAES; DIAZ, 2013).

Na infância, a família é considerada o principal apoio ao indivíduo e interfere no desenvolvimento da criança. Os psicólogos da área têm se interessado na forma como os pais influenciam o desenvolvimento e as competências sociais da criança. A relação entre pais e filhos é formada por um conjunto de atitudes e seu estudo tem sido desenvolvido por meio dos estilos parentais. $\mathrm{O}$ conceito de estilos parentais refere-se a um conjunto de atitudes (disciplina, hierarquia e apoio emocional) que são expressas pelos pais em relação aos filhos (BENCHAYA et al., 2011; DARLING; STEINBERG, 1993).

\section{Estilos Parentais}

O estudo dos estilos parentais teve início com Baumrind (1966) que propôs três modelos teóricos de classificação dos pais (autoritários, autoritativo e permissivos), de acordo com o grau de controle que estes exerciam sobre seus filhos. Pais autoritários tentam moldar, controlar, avaliar o comportamento e as atitudes da criança, valorizam a obediência e atuam com medidas punitivas quando necessário. Esses pais fornecem ambiente com regras claramente estabelecidas. Já os pais de estilo autoritativo tentam direcionar as atividades da criança de forma racional, de maneira orientada para o problema. Exercem um controle firme, mas não impõem à criança muitas restrições. Impõem sua perspectiva como adulto, mas reconhecem os interesses individuais da criança e incentivam o diálogo. Pais permissivos tentam se comportar de forma não punitiva, aceitando os desejos e ações da criança, dando explicações para as regras da família. A criança participa junto com os pais na tomada das decisões. Esses pais são pouco exigentes com os filhos.

Alguns anos depois, o estilo parental permissivo foi dividido em outros dois estilos (indulgente e negligente) por Maccoby e Martin (1983), baseado em duas dimensões: exigência e responsividade. $\mathrm{O}$ termo responsividade refere-se às atitudes 
compreensivas, amorosas e de envolvimento dos pais com seus filhos (afeto), e a exigência refere-se ao estabelecimento e cumprimento de regras (controle), caracterizando os estilos parentais em: autoritários (são exigentes e não responsivos); autoritativos (são exigentes e responsivos); indulgentes (são responsivos e não exigentes); negligentes (não são exigentes nem responsivos).

Baseado nos conceitos de Maccoby e Martin (1983), Lamborn et al. (1991) desenvolveram as escalas de responsividade e exigência classificando o estilo parental. Essas escalas foram traduzidas no Brasil por Costa, Teixeira e Gomes (2000) e posteriormente adaptada para crianças por Weber et al. (2004).

Os estilos parentais são investigados por influenciarem diferentemente o desenvolvimento infantil. Dessa forma, alguns autores começaram a investigar se existe relação entre as práticas de alimentação infantil utilizada pelos pais e os estilos parentais (BLISSETT; HAYCRAFT, 2008). Muitos estudos já foram desenvolvidos nessa área e descobriram relações entre os estilos parentais e diferentes aspectos no desenvolvimento da criança como, hábito de estudo, rendimento escolar, envolvimento com drogas e obesidade (COHEN; RICE, 1997; FONSECA et al., 2014; KAKINAMI et al., 2015; PECKAM; LOPEZ, 2006).

\section{Imagem Corporal}

Os fatores ambientais são importantes no desenvolvimento dos padrões culturais que estabelecem normas e influenciam na forma como o indivíduo se percebe e como idealiza a sua aparência. Segundo Cash (2004) a aparência física pode afetar de diferentes maneiras a vida do indivíduo. De acordo com Slade (1994) a imagem corporal seria definida como a imagem que se tem na mente sobre o tamanho e a forma do próprio corpo, e pode ser dividida em dois componentes: o perceptivo e o atitudinal. A imagem corporal engloba todas as formas pelas quais o sujeito experiência e conceitua seu próprio corpo, sua forma e tamanho. Sendo influenciada por fatores sensoriais, por processos de desenvolvimento e aspectos psicodinâmicos. A imagem corporal deve ser compreendida como um fenômeno singular, estruturada não apenas nas experiências do indivíduo. Se referindo às experiências psicológicas e não apenas a aparência física. Abrangem a autopercepção e atitudes relacionadas ao corpo como pensamentos, crenças, comportamentos e sentimento (CASH, 2004; TAVARES, 2003). 
No início dos estudos com imagem corporal acreditava-se que a imagem do corpo era relevante apenas para mulheres e meninas, e que dizia respeito apenas ao peso e à forma do corpo. Essa era uma visão limitada, estudo recentes demonstraram que homens e crianças também apresentam preocupações desse tipo (CASH, 2004; COCCHETO; PENÃ; PELLANDA, 2015).

A percepção dos pais sobre a imagem corporal dos seus filhos tem sido muito estudada, por se considerar que uma percepção alterada por parte dos pais, pode determinar ou influenciar diversos comportamentos nas crianças. Nota-se uma tendência dos pais de subestimarem o peso dos filhos não reconhecendo o sobrepeso ou até mesmo a obesidade destes. A percepção materna sobre o peso do filho parece ser influenciada pelo sexo, pela idade, pelo peso da criança e pela escolaridade da mãe (CHUPROSKI; DE MELLO, 2009).

Uma das causas para a não percepção do peso dos filhos pelos pais parece ser cultural. O fato é que crianças "gordinhas" ainda são vistas como tendo boa saúde, como se estas fossem melhor cuidadas pelos pais. Muitas mães acreditam que esse excesso de peso será uma situação passageira, que a criança perderá peso com o crescimento, e que este não se tornará um adulto obeso (BAUGHCUM et al., 2000).

Essa percepção inadequada por parte dos pais dificulta o tratamento da obesidade infantil. Uma vez que, se eles não perceberem o problema, não vão procurar ajuda e mesmo com o auxílio de profissionais, podem não se empenhar em ajudar a criança, já que não veem risco real para ela. Aumentar a conscientização dos pais em relação ao problema de peso dos filhos é o primeiro passo no tratamento da obesidade pediátrica (MEIZI; EVANS, 2007).

A insatisfação corporal é usada para avaliar a diferença entre a imagem corporal real percebida pelo indivíduo e a imagem corporal idealizada. Os padrões de beleza mudam constantemente e embora a prevalência de sobrepeso e obesidade tenha aumentado nas últimas décadas, atualmente o que tem predominado é a imagem de mulheres com corpos magros/definidos e homens com corpos musculosos. A influência sociocultural é um fator importante para influenciar a forma ideal de corpo e a insatisfação com o mesmo (NEIGHBORS; SOBAL, 2007).

A insatisfação com a imagem corporal começa na infância. Já está claro na literatura a preocupação de algumas crianças em estar com boa aparência para serem aceitas pelos outros. As crianças estão cada vez mais precocemente modificando o que 
comem e estão se preocupando em fazer exercícios aeróbicos com o intuito de perder peso, incomodados com a sua aparência e forma física. Essas questões aumentam o interesse por pesquisas com imagem corporal, o que tem contribuído nos últimos anos para o aumento de estudos deste caráter em crianças e adolescentes (COCCHETTO, 2015; LEITE, 2014; SMOLAK 2004).

Os estudos com imagem corporal no Brasil ganharam enorme avanço após a construção da escala de silhuetas elaborada a partir de fotos reais de sujeitos brasileiros retratando o seu biotipo. Desta maneira, as pesquisas realizadas no Brasil não necessitam utilizar as escalas de silhuetas disponíveis na literatura internacional, construídas a partir de sujeitos que podem não se enquadrar no biotipo do brasileiro. Após a elaboração da escala para adultos também foi produzida a escala para crianças e adolescentes, possibilitando estudos com uma ampla faixa etária (KAKESHITA; ALMEIDA 2006; KAKESHITA et al., 2009). 


\section{JUSTIFICATIVA}

Com o aumento acelerado da obesidade infantil, faz-se necessário o desenvolvimento de mais estudos que possibilitem identificar os fatores que desencadeiam essa patologia, pois, o excesso de peso na infância aumenta a suscetibilidade da criança tornar-se um adulto obeso precocemente. $\mathrm{O}$ ambiente familiar pode constituir em um fator de risco para a obesidade. A percepção inadequada do tamanho corporal dos filhos por parte dos pais é um dos principais obstáculos que dificulta o tratamento da obesidade infantil. Entender como a criança se percebe e também como os pais influenciam a percepção da criança e como os pais percebem o tamanho corporal dos filhos, ajudaria na elaboração de estratégias individualizadas, para o diagnóstico nutricional correto e, posteriormente, no tratamento. Tornar os pais conscientes de que a obesidade é um sério problema de saúde, pode ser o primeiro passo na promoção de hábitos de vida mais saudáveis.

Os estilos parentais influenciam de diferentes formas o desenvolvimento infantil. Entender melhor a influência exercida pelos pais sobre os filhos e a relação entre o estilo parental e o estado nutricional e prática de atividade física das crianças pode nos ajudar a compreender os fatores que estão envolvidos na obesidade infantil bem como na sua prevenção. 
ESTUDO 1 


\section{OBJETIVOS}

\subsection{OBJETIVO GERAL}

Verificar a influência dos estilos parentais no estado nutricional e prática de atividade física das crianças.

\subsection{OBJETIVOS ESPECÍFICOS}

- Avaliar o estado nutricional dos estudantes através da aferição do peso corporal e estatura para posterior cálculo do Índice de Massa Corporal (IMC).

- Avaliar a correlação entre o IMC dos pais e o IMC dos filhos.

- Verificar a frequência e intensidade de atividade física dos estudantes através do Questionário para Avaliar as Atividades Físicas de Crianças e Adolescentes.

- Avaliar e comparar os estilos parentais percebidos pelos filhos e pelos próprios pais através da Escala de Exigência e Responsividade.

- Investigar a relação entre IMC da criança e os estilos parentais percebidos pelas mesmas.

- Avaliar a relação entre os estilos parentais percebidos pelos estudantes e a prática de Atividade Física. 


\section{METODOLOGIA}

\subsection{PARTICIPANTES}

Foram convidados a participar da pesquisa 433 estudantes, com idade entre nove e 12 anos, matriculados do quarto ao sétimo ano de três escolas do ensino fundamental, sendo duas particulares e uma da rede pública de ensino. Juntamente com o estudante foram convidados aparticpar um de seus pais ou na ausência dos pais, uma pessoa responsável pelo estudante.

\subsection{ASPECTOS ÉTICOS}

O projeto foi cadastrado na Plataforma Brasil e aprovado pelo Comitê de Ética em Pesquisa com Seres Humanos da Faculdade de Filosofia, Ciências e Letras de Ribeirão Preto Universidade de São Paulo/ Campus Ribeirão Preto (CAAE ${ }^{\circ}$ 50830715.9.0000.5407).

Foi fornecido aos responsáveis o Termo de Consentimento Livre e Esclarecido (TCLE) (APÊNDICES A, B e C) que teve como objetivo fornecer as informações sobre a pesquisa (tema, objetivos, metodologia, potenciais perigos, desconfortos e dados para contato com os pesquisadores) e possibilitou a decisão sobre sua participação, formalizado através da assinatura do termo.

\subsection{LOCAL DA PESQUISA}

A pesquisa foi realizada na sala de aula dos próprios alunos. Em todas as escolas, os responsáveis receberam o TCLE e, somente após consentimento, os estudantes foram incluídos no estudo.

\subsection{INSTRUMENTOS}

\section{Identificação da Criança:}

Foi utilizado um questionário (APÊNDICE D) para a caracterização da amostra, obtendo informações tais como: data de nascimento, idade, sexo, período em que estuda, quais e quantas pessoas residem na casa, número de irmãos, e a situação conjugal dos pais. 


\section{Exigência e Responsividade (EER):}

Foram utilizadas as Escalas de Exigência e de Responsividade (EER), (ANEXO A) adaptada e validada por Weber et al. (2004). Contêm 16 questões divididas em duas escalas: dez perguntas que medem o quanto a criança percebe seus pais como amorosos, responsivos e envolvidos (responsividade); e seis perguntas que medem o quanto os pais monitoram e supervisionam a criança (exigência).

\section{Questionário para avaliar as atividades físicas de crianças e adolescentes}

Para avaliar a atividade física e o sedentarismo dos estudantes foi utilizado o questionário, elaborado por Silva (2009) (ANEXO B) através de modificações e adaptações dos principais questionários para avaliar a atividade física de crianças e adolescentes. Este questionário contem quatro itens: meio de deslocamento para a escola, atividades físicas realizadas dentro e fora da escola e o tempo de inatividade, descrito como o tempo gasto assistindo televisão, jogando videogames e conversando ao telefone.

\section{Identificação do responsável}

Para a caracterização dos responsáveis foram coletadas as informações como nome, idade, sexo, grau de parentesco com a criança, escolaridade, profissão, número de filhos, estado civil, altura e peso (APÊNDICE E).

\section{Escala de Exigência e Responsividade - pais (EER):}

Para viabilizar a aplicação do mesmo instrumento aos pais, foi utilizada a Escala de Exigência e Responsividade com adaptação na construção das frases, portanto os pais responderam sobre seus próprios comportamentos (ANEXO C).

\section{Critério de Classificação Econômica Brasil (CCEB):}

Desenvolvido pela Associação Brasileira de Empresas de Pesquisa (ABEP, 2015), para analisar o poder aquisitivo das participantes do presente estudo classificando em grandes classes (A, B1, B2, C1, C2, DE). Esse sistema enfatiza sua função de estimar o poder de compra das pessoas e das famílias urbanas e rurais, abandonando a pretensão de classificar a população em termos de "classes sociais". As 
classes econômicas são classificadas do maior (A) ao menor (E) poder aquisitivo. Foi utilizado o modelo de questionário sugerido pela Associação Brasileira das Empresas de Pesquisa, para aplicação (ANEXO D) (ABEP, 2015).

\subsection{PROCEDIMENTO}

\subsubsection{Coleta de dados com criança e adolescentes}

As escolas disponibilizaram uma sala de aula para a realização da pesquisa, que foi conduzida em horário de aula e teve duração aproximada de 40 minutos. Cada aluno foi convidado a responder aos questionários em grupo, com a pesquisadora para orientar eventuais dúvidas.

A avaliação antropométrica foi realizada individualmente, de acordo com as recomendações estabelecidas pelo Sistema de Vigilância Alimentar e Nutricional (SISVAN) em seu Manual de Orientações básicas para a coleta, o processamento, a análise de dados e a informação em serviços de saúde (MINISTÉRIO DA SAÚDE, 2004).

Para aferição do peso, os participantes estavam descalços e com roupas leves sem adorno que possa interferir no resultado final do peso, como pulseiras, cintos, relógios, celulares, chaves, bolsas, entre outros. A criança foi posicionada no centro e de costas para o leitor, mantendo-se ereta, com os braços estendidos ao longo do corpo, pés alinhados e olhando para o horizonte, sem se movimentar.

Para aferição da estatura do aluno, o mesmo continuou descalço, com a cabeça livre de adereços, no centro do equipamento, mantendo-se ereto, com os braços estendidos ao longo do corpo, os pés alinhados e paralelos, a cabeça erguida, olhando para um ponto fixo na altura dos olhos.

\subsubsection{Coleta de dados com os responsáveis}

A coleta de dados com um dos pais dos estudantes foi realizada após a reunião bimestral de pais e mestres. Os questionários CCEB, Escala de Exigência e Responsividade e o Questionário elaborado para a caracterização da amostra foram entregues para os pais preencherem em casa e devolverem posteriormente à escola 
através dos estudantes.

\subsection{ANÁLISE DOS DADOS}

Foi calculado o Índice de Massa Corporal (dividindo o peso pelo quadrado da altura). Para as crianças o diagnóstico foi dado de acordo com os valores de percentil do IMC, preconizados pela Organização Mundial da Saúde (2007) (FIGURA 1).

FIGURA1- Classificação dos limites de Percentis para IMC de crianças e adolescentes de 5 a 19 anos, segundo a classificação da OMS, 2007.

\begin{tabular}{|c|c|}
\hline Classificação & Percentil \\
\hline Magreza Grave & $<0,1$ \\
\hline Magreza & $>0,1<3$ \\
\hline Eutrofia & $\geq 3 \leq 85$ \\
\hline Sobrepeso & $>85 \leq 97$ \\
\hline Obesidade & $>97 \leq 99,9$ \\
\hline Obesidade Grave & $>99,9$ \\
\hline
\end{tabular}

Fonte: OMS (2007).

Para os responsáveis o diagnóstico foi feito segundo a classificação da OMS (2000) (FIGURA 2).

FIGURA 2 - Classificação dos limites de IMC para adulto.

\begin{tabular}{|c|c|}
\hline Classificação & $\mathrm{IMC}\left(\mathrm{kg} / \mathrm{m}^{2}\right)$ \\
\hline Baixo Peso & $<18,5$ \\
\hline Eutrófico & $18,5-24,9$ \\
\hline Sobrepeso & $25,0-29,9$ \\
\hline Obesidade Grau I & $30,0-34,9$ \\
\hline Obesidade Grau II & $35,0-39,9$ \\
\hline Obesidade Grau III & $>40,00$ \\
\hline
\end{tabular}

Fonte: OMS (2000). 
Para determinar o estilo parental, as escalas (exigência e responsividade) foram avaliadas por um sistema Likert de três pontos, cada item possui um valor: de um a três pontos. Foi usada a mediana da amostra para considerar um escore alto ou baixo em ambas as dimensões. Por meio dos escores das duas escalas foram classificados os estilos parentais (FIGURA 3).

FIGURA 3 - Classificação dos estilos parentais de acordo com a pontuação nas escalas de exigência e responsividade.

\begin{tabular}{|c|c|c|}
\hline Classificação & $\begin{array}{c}\text { Pontuação na Escala de } \\
\text { Exigência }\end{array}$ & $\begin{array}{c}\text { Pontuação na Escala de } \\
\text { Responsividade }\end{array}$ \\
\hline Autoritativo & Acima da mediana & Acima da mediana \\
\hline Autoritário & Acima da mediana & Abaixo da mediana \\
\hline Permissivo & Abaixo da mediana & Acima da mediana \\
\hline Negligente & Abaixo da mediana & Abaixo da mediana \\
\hline
\end{tabular}

Fonte: Weber (2004)

Em relação à atividade física, os jovens foram classificados de acordo com a frequência e intensidade dos exercícios realizados em: Inativos, se não realizam nenhuma atividade física; Inadequadamente Ativos, se realizam atividade física numa frequência de duas vezes por semana; Ativos se realizam alguma atividade três vezes ou mais por semana. O período sem realizar atividade física foi dividido entre os que passam mais ou menos de três horas ao dia em atividades sedentárias.

\subsection{ANÁLISE ESTATÍSTICA}

O coeficiente de Correlação Linear de Pearson foi utilizado para avaliar o nível de associação entre as variáveis testadas. Foi realizada também a Análise de Variância (ANOVA) seguida do teste de Newman-Keuls, quando apropriado. Foram adotados os programas de software SPSS (versão 17.0) e Statistica (versão 13.0). O nível de significância fixado foi de $\mathrm{p}<0,05$. 


\section{RESULTADOS E DISCUSSÃO}

Das 866 pessoas convidadas, 573 iniciaram a participação, mas apenas 308 concluíram todas as etapas do estudo. Participaram 154 estudantes e seus respectivos responsáveis, a média de idade dos estudantes foi de 9,9 \pm 0,94 anos. A caracterização da amostra encontra-se na Tabela 1.

TABELA 1- Caracterização descritiva dos estudantes de três escolas do ensino fundamental (n=154). Ribeirão Preto, 2017.

\begin{tabular}{lcc}
\hline \multicolumn{1}{c}{ Variável } & $\mathrm{N}$ & $\%$ \\
\hline Gênero & & \\
Masculino & 80 & 52,0 \\
Feminino & 74 & 48,0 \\
Estado socioeconômico & & \\
A & 37 & 24,0 \\
B1 & 38 & 24,7 \\
B2 & 48 & 31,2 \\
C1 & 18 & 11,7 \\
C2 & 12 & 7,8 \\
D-E & 1 & 0,6 \\
Escola & & \\
Particular & 81 & 52,6 \\
Pública & 73 & 47,4 \\
\hline
\end{tabular}

\section{Estado nutricional dos estudantes}

A Tabela 2 descreve as frequências absoluta e relativa da classificação do estado nutricional dos estudantes. Do total, 53,2\% foram classificados como eutróficos e mais de $40 \%$ estava acima do peso (somando-se a porcentagem de sobrepeso, obesidade e obesidade grave).

Os resultados encontrados foram semelhantes aos dados da literatura. No estudo de Rivera et al. (2014) os autores realizaram uma revisão sistemática da literatura para estimar a prevalência de sobrepeso e obesidade em crianças de 0 a 19 anos na América Latina. As prevalências seguindo a classificação da OMS (2007) foram 18,9\% para sobrepeso e $36,9 \%$ para obesidade em crianças em idade escolar, demonstrando que mais de 55\% das crianças nesta faixa etária estariam acima do peso. Segundo os dados do ERICA (2016), estudo que avaliou mais de 70 mil adolescentes de todas as regiões do Brasil, a prevalência de adolescentes acima do peso é de $28,5 \%$. 
TABELA 2. Frequência absoluta e relativa da classificação do estado nutricional segundo a classificação da OMS (2007) dos estudantes ( $\mathrm{n=154)}$ de três escolas do ensino fundamental. Ribeirão Preto, 2017.

\begin{tabular}{lcc}
\hline & N & \% \\
\hline Magreza grave & 1 & 0,6 \\
Magreza & 4 & 2,6 \\
Eutrófia & 82 & 53,2 \\
Sobrepeso & 36 & 23,4 \\
Obesidade & 27 & 17,5 \\
Obesidade grave & 4 & 2,6 \\
Total & 154 & 100 \\
\hline
\end{tabular}

No presente estudo obtivemos uma correlação positiva entre o IMC dos filhos com o IMC de seus pais $(\mathrm{r}=0,3 \mathrm{p}<0,01)$, mostrando que esse problema não é único e exclusivo da criança e sim, algo que deve ser trabalhado e tratado em conjunto com toda a família. Corroborando com os nossos dados Giugliano et al. (2004) também encontraram uma associação entre a obesidade nos pais e a sobrepeso e obesidade nos filhos.

\section{Frequência dos Estilos Parentais avaliados pelas crianças}

Em relação ao estilo parental, o mais frequente no estudo foi o autoritativo com $85,2 \%$, seguido do indulgente com 10,4\% (TABELA 3). O estilo parental dos pais foi classificado somando a pontuação da mãe e do pai, sendo então classificado o estilo parental do casal/família. Para esta análise foram excluídos os participantes que obtiveram pontuação igual à mediana e aqueles que tinham um dos pais falecidos.

As pontuações dos estudantes nas escalas de exigência e responsividade foram altas (a pontuação variava de 6 a 18 pontos e 10 a 30 pontos, respectivamente). A média de pontuação na escala de exigência dos pais foi de 14,2 $\pm 3,6$ pontos e das mães foi de $15,5 \pm 2,6$ pontos. A média de pontuação na escala de responsividade dos pais foi de $24,5 \pm 5,8$ pontos e das mães foi de $26,7 \pm 3,0$ pontos. 
TABELA 3. Frequência relativa e absoluta dos estilos parentais, por casal $(n=135)^{*}$, Ribeirão Preto, 2017.

\begin{tabular}{lccc}
\hline & $\begin{array}{c}\text { Todos os alunos } \\
\mathbf{N}(\%)\end{array}$ & $\begin{array}{c}\text { Escola Pública } \\
\mathbf{N}(\%)\end{array}$ & $\begin{array}{c}\text { Escola Particular } \\
\mathbf{N}(\%)\end{array}$ \\
\hline Autoritativo & $115(85,2)$ & $47(78,3)$ & $68(90,7)$ \\
Autoritário & $3(2,2)$ & $3(5,0)$ & 0 \\
Indulgente & $14(10,4)$ & $7(11,7)$ & $7(9,3)$ \\
Negligente & $3(2,2)$ & $3(5,0)$ & 0 \\
Total & $135(100)$ & $60(100)$ & $75(100)$ \\
\hline
\end{tabular}

*Foram excluídos os participantes que obtiveram pontuação igual à mediana e aqueles que tinham um dos pais falecidos, conforme instrução do instrumento, pois a pontuação é dada somando-se a pontuação da mãe e do pai.

Weber, Brandenburg e Viezzer (2003) avaliaram 280 crianças da quarta série com idade entre nove e 12 anos para identificar a relação do estilo parental com comportamentos de otimismo das crianças. As frequências dos estilos parentais da família foram as seguintes: 38,3\% foram classificados como sendo autoritários e negligentes, o restante ficou dividido entre pais indulgentes e autoritários, $11,4 \%$ e $12,1 \%$, respectivamente.

Kakinami et al. (2015) realizaram um estudo com mais de 37 mil crianças canadenses em idade pré-escolar e escolar e encontraram dados semelhantes com o estudo de Weber, Brandenburg e Viezzer (2003). Mais da metade das crianças (com idade entre seis e 11 anos) classificaram seus pais como sendo autoritativos e negligentes $(31,9 \%$ e $31,1 \%$, respectivamente).

Em ambos os estudos citados, a grande maioria dos pais foram classificados nos dois estilos nos pontos extremos da classificação dos estilos parentais. Ou são muito exigentes e responsivos (autoritativos) ou são pouco exigentes e pouco responsivos (negligentes). Na nossa amostra o estilo negligente foi pouco encontrado, o que de certa forma é um bom indicativo de que os pais estão sabendo dosar as suas atitudes perante os filhos.

Não encontramos relação entre os estilos parentais e o estado nutricional dos 
estudantes como foi observado no estudo canadense, que encontrou que mães autoritárias tinham uma maior chance dos filhos apresentarem excesso de peso no futuro quando comparadas ás mães autoritativas.

Já em um estudo realizado no Brasil por Mayer et al. (2014) em 139 alunos com idade entre dez e 14 anos, que também utilizou a escala de exigência e responsividade adaptada e validada para crianças por Weber et al. (2004), foi observado que crianças com mais peso estavam em famílias com estilo permissivo.

Houve então divergência entre os estudos que relacionam o estilo parental com o estado nutricional das crianças. Mostrando que apesar de haver uma tendência de que famílias autoritativas protegem a criança contra o excesso de peso, isso ainda não está totalmente elucidado na literatura, demonstrando que este assunto é de extrema complexidade e que possivelmente envolve vários fatores como ambientais, culturais e psicológicos.

\section{Prática de Atividade Física}

Quase metade dos alunos $(41,6 \%)$ foram considerados inativos e mais de $45 \%$ relatou passar mais de três horas por dia em atividades sedentárias como: assistindo à televisão, jogando vídeo game, no celular e no computador ou tablet (TABELA 4).

Esses dados se assemelham com os estudos de Perine et al. (2006) que ao analisarem composição corporal, atividade física e consumo alimentar em mais de 400 estudantes do ensino fundamental encontraram que 54\% eram insuficientemente ativos. Em relação ao tempo de inatividade física, os dados do ERICA (2016), encontrou que mais de $70 \%$ dos adolescentes com idade entre 12 e 14 anos permanecem mais de duas horas por dia em atividades sedentárias. Esses dados são bem superiores aos que encontramos, uma das explicações seria de que os alunos tiveram dificuldade em quantificar o tempo que passa nessas atividades. Os estudantes apresentaram dificuldade em responder ao certo quantas horas por dia passavam em frente ao celular por exemplo. 
TABELA 4. Frequência absoluta e relativa da prática de atividade física e horas inativas dos estudantes $(n=154)$, de três escolas do ensino fundamental. Ribeirão Preto, 2017.

\begin{tabular}{lccc}
\hline & $\begin{array}{c}\text { Todos } \\
\text { N (\%) }\end{array}$ & $\begin{array}{c}\text { Escola Particular } \\
\text { N (\%) }\end{array}$ & $\begin{array}{c}\text { Escola Pública } \\
\text { N (\%) }\end{array}$ \\
\hline Prática de Atividade Física & & & \\
Ativos & $39(25,3)$ & $19(23,5)$ & $20(27,4)$ \\
Inadequadamente ativo & $51(33,1)$ & $36(44,4)$ & $15(20,5)$ \\
Inativo & $64(41,6)$ & $26(32,0)$ & $38(52,1)$ \\
Total & $154(100)$ & $81(100)$ & $73(100)$ \\
Atividade sedentária & & & \\
Menos de 3hrs/dia & $71(46,1)$ & $40(49,3)$ & $31(42,5)$ \\
Mais de 3hrs/dia & $83(53,9)$ & $41(50,6)$ & $42(57,3)$ \\
Total & $154(100)$ & $81(100)$ & $73(100)$ \\
\hline
\end{tabular}

Foi observado no presente estudo efeito significativo entre a pontuação na escala de exigência e a prática de atividade física $\left[\mathrm{F}_{(2,87,9)}=3,3 ; \mathrm{p}<0,05\right]$. $\mathrm{O}$ teste post-hoc demonstrou que a média de pontuação na escala de exigência dos estudantes classificados como inadequadamente ativos foi maior que a média de pontuação dos estudantes classificados como inativos. Ou seja, as crianças inativas foram aquelas que pontuaram menos na escala de exigência, sugerindo que, filhos de pais menos exigentes, praticam menos atividade física.

\section{Caracterização dos responsáveis}

A idade média dos participantes foi de 38,9 \pm 7,2 anos e a maioria relatou ter concluído no mínimo ensino médio. A participação das mães no estudo foi maior $(83,8 \%)$ que a dos pais. A caracterização da amostra dos responsáveis encontra-se na Tabela 5. Enquanto que $85,2 \%$, dos estudantes classificaram seus pais como sendo autoritativos, a grande maioria dos pais $(99,2 \%)$ ao responderem o mesmo questionário, analisando e relatando seus próprios comportamentos, foram classificados como sendo do estilo autoritativo.

Weber et al. (2004) ao realizarem um estudo com crianças e seus respectivos pais ou responsáveis e compararem os estilos parentais observados pelos filhos e os relatados pelos próprios pais, também encontraram que a pontuação total nas duas escalas foi bem maior na quando respondida pelos pais e pelas mães do que a escala 
respondida pelos filhos. Como no nosso estudo isso pode ter acontecido porque os pais podem sentir-se sugestionados a responderem de maneira socialmente correta e também por acreditarem que tudo o que fazem é da melhor forma, enquanto que os filhos têm uma percepção diferente da atitude dos pais perante a eles.

TABELA 5. Frequência relativa e absoluta da caracterização da amostra dos responsáveis pelos estudantes (n=154). Ribeirão Preto, 2017.

\begin{tabular}{lc}
\hline \multicolumn{1}{c}{ Variáveis } & N (\%) \\
\hline Escolaridade & $7(4,5)$ \\
Fundamental incompleto & $9(5,8)$ \\
Fundamental completo & $3(1,9)$ \\
Médio incompleto & $63(40,9)$ \\
Médio completo & $57(37,0)$ \\
Superior Completo & $15(9,7)$ \\
Pós graduação & \\
Estado nutricional & $68(44,2)$ \\
Eutrófico & $47(30,5)$ \\
Sobrepeso & $26(16,9)$ \\
Obesidade grau I & $11(7,1)$ \\
Obesidade grau II & $2(1,3)$ \\
Obesidade grau III & \\
\hline
\end{tabular}

Não foram encontradas diferenças estatísticas entre as variáveis: estilos parentais e IMC dos estudantes. Isso pode ter ocorrido devido à pouca variação dentro dos quatro estilos parentais da amostra estudada, pois mais de $80 \%$ da amostra se concentrou em um estilo parental. Também não obtivemos diferença estatística em relação a situação conjugal dos pais e o IMC dos filhos. 


\section{CONCLUSÕES}

A porcentagem de estudantes acima do peso foi alta e houve correlação entre o IMC dos estudantes e dos seus pais. Em relação a prática de atividade física, uma pequena parcela dos estudantes são ativos fisicamente.

O estilo parental mais frequente avaliado tanto pelas crianças quanto pelos pais foi o autoritativo; não houve relação entre o estado nutricional da criança e o estilo parental dos pais. Porém, observamos que filhos de pais menos exigentes, praticam menos atividade física. 
ESTUDO 2 


\section{OBJETIVOS}

\subsection{OBJETIVO GERAL}

Avaliar a acurácia e a satisfação dos estudantes com o seu tamanho corporal.

\subsection{OBJETIVOS ESPECÍFICOS}

- Avaliar a acurácia da percepção corporal do estudante através da Escala de Figuras de Silhuetas (EFS) infantil.

- Avaliar a satisfação dos estudantes com o seu tamanho corporal através da EFS infantil.

- Avaliar a acurácia da percepção dos pais em relação ao tamanho corporal dos filhos.

- Avaliar a satisfação dos pais em relação ao tamanho corporal dos filhos.

- Avaliar a percepção do estudante sobre como a mãe/ o pai a percebe através da EFS infantil.

- Avaliar como essa percepção dos pais pode interferir na acurácia dos filhos em relação a sua própria imagem corporal.

- Avaliar a percepção do estudante sobre como a mãe/ o pai gostaria que ela fosse através da EFS infantil.

- Avaliar a relação entre a satisfação do estudante com o seu próprio corpo e a satisfação dos pais em relação ao tamanho corporal dos filhos.

- Avaliar qual foi a figura mais escolhida entre os estudantes como sendo a mais próxima do seu tamanho atual e a figura mais escolhida como sendo a silhueta ideal.

- Avaliar a diferença entre meninos e meninas quanto à acurácia e à satisfação em relação ao seu tamanho corporal. 


\section{METODOLOGIA}

Participaram deste estudo os mesmos sujeitos do estudo 1, ou seja, 154 estudantes e seus respectivos pais totalizando uma amostra de 308 participantes.

\section{1 INSTRUMENTOS}

\section{Escala de Figuras de Silhuetas infantil (EFS):}

A EFS infantil (ANEXO E) foi utilizada para avaliar a acurácia/inacurácia da percepção corporal e a satisfação/insatisfação com o tamanho corporal. Desenvolvido e validado para a população brasileira por Kakeshita et al. (2009), as imagens nas figuras são condizentes com o biótipo brasileiro, considerando estatura média e as variações de IMC. Consiste numa escala de 11 cartões para crianças apresentados de forma ascendente, com variações progressivas na escala de medidas, com IMC variando de 12 a $29 \mathrm{~kg} / \mathrm{m}^{2}$. Foram considerados os IMC correspondentes às figuras escolhidas, comparados ao IMC real, obtido pela aferição de peso e estatura durante a coleta. A EFS também foi utilizada para avaliar a percepção dos pais em relação ao tamanho corporal dos filhos.

\subsection{PROCEDIMENTOS}

8.2.1. Coleta de dados com criança e adolescentes

As escolas disponibilizaram uma sala de aula para a realização da pesquisa, que foi conduzida em horário de aula e teve duração aproximada de 40 minutos. Individualmente, foi aplicada a EFS infantil que estava disposta em uma mesa plana em série ordenada ascendente e foram feitas quatro perguntas: "Como você se vê?", "Como você gostaria de ser?", “Como você acha que a sua mãe/seu pai te vê?", Como você acha que a sua mãe/seu pai gostaria que você fosse?”.

A avaliação antropométrica foi descrita anteriormente no estudo 1.

\subsubsection{Coleta de dados com os responsáveis}

A coleta de dados com um dos responsáveis pelo estudante foi realizada após a reunião bimestral de pais e mestres e/ou com horário marcado, quando necessário. Após a assinatura do TCLE foi disponibilizada EFS infantil em uma mesa plana em série ordenada ascendente. 


\subsection{ANÁLISE DOS DADOS}

Para a tabulação e análise dos dados foram calculados o IMC real (dos estudantes) a partir do peso e altura coletados, o IMC atual a partir da resposta da pergunta: "Como você se vê?", e para classificação da satisfação/insatisfação com a imagem corporal foi considerada a diferença entre o IMC “desejado" (“Como você gostaria de ser?”) e IMC atual.

Para avaliar a acurácia dos responsáveis foi calculado o IMC atual percebido pelos pais através da resposta da pergunta "Como você vê seu fillho?" e para avaliar a satisfação dos responsáveis com a imagem corporal dos filhos foi calculado o IMC desejado pelos pais a partir da resposta da pergunta: e "Como você gostaria que ele fosse?". Quanto mais próxima de zero, mais acurada foi a estimação e menor a insatisfação. Resultados negativos indicaram uma subestimação do tamanho corporal real e um anseio por uma silhueta menor, enquanto resultados positivos indicaram superestimação e um desejo por uma silhueta maior.

\subsection{ANÁLISE ESTATÍSTICA}

O coeficiente de Correlação Linear de Pearson foi utilizado para avaliar o nível de associação entre as variáveis testadas. Foi realizada também a Análise de Variância (ANOVA) seguida do teste de Newman-Keuls, quando apropriado. Foram adotados os programas de software SPSS (versão 17.0) e Statistica (versão 13.0). O nível de significância fixado foi de $\mathrm{p}<0,05$. 


\section{RESULTADOS E DISCUSSÃO}

A média do IMC dos estudantes foi de $19,33 \pm 4,31 \mathrm{~kg} / \mathrm{m}^{2}$ e dos responsáveis foi de $26,89 \pm 4,97 \mathrm{~kg} / \mathrm{m}^{2}$ (TABELA 6$)$.

TABELA 6 - Média e desvio padrão das variáveis antropométricas dos estudantes e de um dos pais ou responsável. Ribeirão Preto, 2017.

\begin{tabular}{lcc}
\hline Variáveis & Média & Desvio Padrão \\
\hline Estudantes $(\mathbf{n}=\mathbf{1 5 4})$ & 9,96 & 0,94 \\
Idade $(\mathrm{anos})$ & 41,60 & 13,83 \\
Peso $(\mathrm{kg})$ & 1,45 & 0,08 \\
Altura $(\mathrm{m})$ & 19,33 & 4,31 \\
IMC Real $\left(\mathrm{kg} / \mathrm{m}^{2}\right)$ & & \\
Responsáveis $(\mathbf{n}=\mathbf{1 5 4})$ & 38,90 & 7,22 \\
Idade $($ anos) & 74,23 & 15,91 \\
Peso $(\mathrm{kg})$ & 1,65 & 0,07 \\
Altura $(\mathrm{m})$ & 26,89 & 4,97 \\
IMC Real $\left(\mathrm{kg} / \mathrm{m}^{2}\right)$ & & \\
\hline
\end{tabular}

\section{Acurácia dos estudantes na percepção do tamanho corporal}

Com relação aos resultados obtidos por meio das Escalas de Silhuetas, observamos que 23,4\% dos alunos apresentaram uma percepção acurada de seu tamanho corporal, enquanto mais de $40 \%$ subestimou o seu tamanho. Não houve diferença entre os alunos da escola pública e das escolas particulares (TABELA 7).

Lelii (2015) avaliou como crianças em idade pré-escolar julgam seu próprio tamanho corporal e como julgam o tamanho corporal dos outros. Foi observado que as crianças julgam um pouco melhor o tamanho corporal quando se trata de outra pessoa. Mostrando que as crianças podem apresentar dificuldade para perceber o seu tamanho corporal real. 
TABELA 7 - Frequência relativa e absoluta da acurácia dos estudantes perante o seu tamanho corporal (n=154). Ribeirão Preto, 2017.

\begin{tabular}{lccc}
\hline & Todos os alunos & Escola Pública & Escola Particular \\
& $\mathbf{N}(\%)$ & $\mathbf{N}(\%)$ & $\mathbf{N}(\%)$ \\
\hline Acurado & $36(23,4)$ & $15(20,5)$ & $21(25,9)$ \\
Subestimam & $67(43,5)$ & $31(42,5)$ & $36(44,4)$ \\
Superestimam & $51(33,1)$ & $27(36,9)$ & $24(29,6)$ \\
Total & $154(100)$ & $73(100)$ & $81(100)$ \\
\hline
\end{tabular}

Ao analisarmos a acurácia na percepção do tamanho corporal separadamente pela classificação do estado nutricional, essa distorção foi maior nos extremos do espectro, ou seja, entre as crianças com baixo peso e obesas. O estudante classificado com magreza grave superestimou seu tamanho corporal enquanto que todas as crianças com obesidade grave subestimaram o seu tamanho corporal (FIGURA 4).

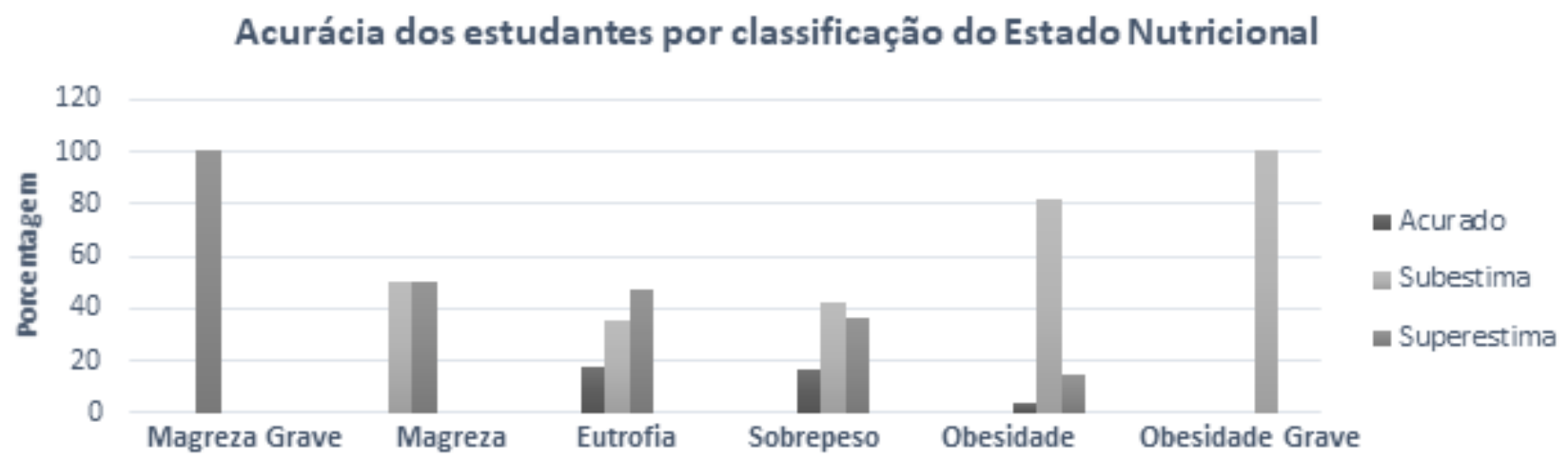

FIGURA 4 - Acurácia da percepção da imagem corporal dos estudantes, de três escolas do ensino fundamental, por estado nutricional (n=154). Ribeirão Preto, 2017.

Corroborando com nossos dados, o estudo de Kornilaki (2015) que comparou o tamanho corporal real com o percebido pela criança, encontrou que entre as crianças eutróficas, $75 \%$ escolheram figuras que representavam tamanho corporal médio, demonstrando uma percepção adequada do seu tamanho corporal. Porém, 86,7\% das crianças com baixo peso superestimaram seu tamanho corporal, enquanto que a maioria das crianças com excesso de peso subestimou (86,9\%). Já Cocchetto, Penã e Pellanda (2015) identificaram que a distorção da imagem corporal foi de 12,2\% nos eutróficos, 
$30,8 \%$ nos com sobrepeso e $42,1 \%$ nos obesos.

Foi observado efeito significativo entre a acurácia dos pais e o índice de massa corporal dos filhos $\left[\mathrm{F}_{(5,36,2)}=6,6 ; \mathrm{p}<0,001\right]$. O teste post-hoc demonstrou que quanto maior o IMC da criança maior era a inacurácia dos pais, demonstrando que os pais também têm dificuldade em perceber o excesso de peso dos filhos quando estes se encontram acima do peso, subestimando o tamanho corporal das crianças. O que pode ser um importante obstáculo no combate ao excesso de peso dos jovens.

\section{Satisfação dos estudantes com o seu tamanho corporal}

A satisfação corporal foi avaliada comparando a imagem (figura) desejada com a imagem (figura) percebida. No que diz respeito à satisfação com a própria imagem, mais de $60 \%$ dos estudantes relataram ser insatisfeitos, sendo que pouco mais da metade dos escolares $(51,4 \%)$ apresentaram desejo por uma silhueta menor (TABELA 8).

TABELA 8 - Frequência relativa e absoluta da satisfação dos estudantes com o seu tamanho corporal $(\mathrm{n}=154)$. Ribeirão Preto, 2017.

\begin{tabular}{lccc}
\hline & Todos os alunos & Escola Pública & Escola Particular \\
& $\mathrm{N}(\%)$ & $\mathrm{N}(\%)$ & $\mathrm{N}(\%)$ \\
\hline Satisfeitos & $53(37,8)$ & $26(35,6)$ & $27(33,3)$ \\
Gostariam de ser & $81(51,4)$ & $36(49,2)$ & $45(55,6)$ \\
menor & & & $9(11,1)$ \\
Gostariam de ser maior & $20(10,8)$ & $11(15,4)$ & $81(100)$ \\
Total & $154(100)$ & $73(100)$ & \\
\hline
\end{tabular}

Nossos resultados foram semelhantes com o estudo realizado por Leite et al. (2014) com crianças de quatro e cinco anos, onde a prevalência de insatisfação foi de $76,9 \%$ e mais da metade dos escolares apontaram como ideal as imagens com tamanho corporal menor do que a atual, demonstrado desejo por ser menor. Esta insatisfação se torna um problema quando até mesmo as crianças que estão no peso ideal, desejam ter uma silhueta menor.

Diferença entre meninos e meninas quanto à acurácia e à satisfação em relação ao seu tamanho corporal. 
Em relação à acurácia, as meninas demonstraram ser mais acuradas na percepção do tamanho corporal que os meninos, $29,7 \%$ contra $17,5 \%$, respectivamente. Os meninos superestimam mais $(42,5 \%)$ o seu tamanho corporal do que as meninas. Já em relação a satisfação com a imagem corporal, 62,2\% das meninas e 68,7\% dos meninos relataram estar insatisfeitos (TABELA 9).

TABELA 9 - Frequência relativa e absoluta da diferença entre a satisfação e acurácia de meninos e meninas $(n=1540)$ em relação ao seu tamanho corporal. Ribeirão Preto, 2017.

\begin{tabular}{lcc}
\hline Variáveis & Meninos & Meninas \\
& $\mathbf{n}(\%)$ & $\mathbf{n}(\%)$ \\
\hline Satisfação & $25(31,3)$ & $28(37,8)$ \\
Satisfeitos & $38(51,4)$ \\
Gostariam de ser menor & $43(53,8)$ & $8(10,8)$ \\
Gostariam de ser maior & $12(15,0)$ & $74(100)$ \\
Total & $80(100)$ & \\
Acurácia & & $22(29,7)$ \\
Acurado & $14(17,5)$ & $33(44,6)$ \\
Subestimam & $34(42,5)$ & $19(25,7)$ \\
Superestimam & $32(40,0)$ & 74 \\
Total & 80 & 74 \\
\hline
\end{tabular}

Ao analisarem a insatisfação da imagem corporal em 79 crianças de sete a 11 anos, Cocchetto, Penã e Pellanda (2015) encontraram dados bastante expressivos e semelhantes com os do presente estudo, em que 75,6\% dos meninos e 76,2\% das meninas relataram estar insatisfeitos com o seu corpo.

Diferentemente dos dados encontrados na literatura como no estudo de Plegrine et al. (2014) onde os meninos demonstraram desejo por silhuetas maiores e as meninas por silhuetas menores, no presente estudo os meninos relataram a preferência por uma silhueta menor tanto quanto as meninas (meninos 53,8\% e meninas 51,4\%).

A figura mais escolhida pelas meninas como sendo a figura que representava o corpo atual foi a figura número quatro $(24,3 \%)$ que representa o IMC entre $16,25 \mathrm{~kg} / \mathrm{m}^{2}$ e $17,9 \mathrm{~kg} / \mathrm{m}^{2}$ seguida das figuras cinco $(18,9 \%)$ e três $(17,6 \%)$. A figura mais escolhida como sendo a desejada foi também a figura de número quatro com $24 \%$ seguido, das figuras três e dois, ambas com 18,9\%. 
Já entre os meninos, a figura mais escolhida como sendo a do seu corpo atual foi a figura de número seis $(22,5 \%)$ que representa o IMC entre $19,65 \mathrm{~kg} / \mathrm{m}^{2}$ e $21,34 \mathrm{~kg} / \mathrm{m}^{2}$ seguido pelas figuras cinco $(18,6)$ e quatro $(11,3)$. As figuras escolhidas como sendo as mais desejadas foram: figura número quatro $(27,5 \%)$, cinco $(23,6 \%)$ e a figura de número três $(22,5 \%)$, demonstrando o desejo dos meninos também por uma silhueta menor.

De acordo com o trabalho de Pereira et al. (2009) que avaliaram a percepção da imagem corporal de 402 crianças e adolescentes, dentre os meninos a silhueta três foi a mais citada como sendo a ideal. Já entre as meninas a silhueta mais citada foi a de número dois.

\section{Acurácia e satisfação dos pais em relação ao tamanho corporal dos fillhos}

Já entre os responsáveis mais de 50\% subestimaram o tamanho corporal de seus filhos e 25,3\% apresentaram uma percepção acurada. Ao compararmos a diferença entre a percepção dos pais com a das mães observamos que os pais demonstraram subestimar mais o tamanho corporal de seus filhos do que as mães $(60,9 \%$ e $52,7 \%$, respectivamente) (TABELA 10).

TABELA 10 - Frequência relativa e absoluta da acurácia e satisfação dos pais em relação ao tamanho corporal dos filhos (n=154). Ribeirão Preto, 2017.

\begin{tabular}{lccc}
\hline \multicolumn{1}{c}{ Variáveis } & $\begin{array}{c}\text { Todos } \\
\text { N (\%) }\end{array}$ & $\begin{array}{c}\text { Mães } \\
\text { N (\%) }\end{array}$ & $\begin{array}{c}\text { Pais } \\
\text { N (\%) }\end{array}$ \\
\hline Acurácia & & & \\
Acurado & $39(25,3)$ & $33(25,6)$ & $6(26,1)$ \\
Subestimam & $82(53,2)$ & $68(52,7)$ & $14(60,9)$ \\
Superestimam & $33(21,4)$ & $28(21,7)$ & $3(13,0)$ \\
Satisfação & & & \\
Satisfeito & $75(48,7)$ & $63(48,8)$ & $10(43,5)$ \\
$\begin{array}{l}\text { Gostariam que fosse } \\
\text { menor } \\
\text { Gostariam que fosse }\end{array}$ & $50(32,5)$ & $44(34,1)$ & $6(26,1)$ \\
\hline
\end{tabular}

Obtivemos uma correlação negativa entre a acurácia dos pais e o IMC dos filhos $(\mathrm{r}=-0,208 \mathrm{p}<0,01)$, demonstrando que quanto maior o IMC da criança, menor era a acurácia dos pais. Esses resultados estão de acordo com o estudo de Aparício et al. (2011) e Parkinson et al. (2012) que observaram que os pais apresentam tendência de 
não perceber o excesso de peso dos filhos. Essa subestimação do tamanho corporal dos filhos pode ser o principal obstáculo na prevenção e/ou tratamento, quando a acriança apresenta excesso de peso.

Em relação à satisfação dos pais perante o tamanho corporal dos filhos, observamos que mais de $50 \%$ são insatisfeitos e mais de $30 \%$ deles demonstraram preferência por uma figura menor do que a figura escolhida como sendo a atual, conforme observamos na tabela abaixo.

Diferentemente do nosso estudo, no trabalho de Duchinet al. (2015) realizado com crianças de cinco a 12 anos e suas mães, foi encontrado que $47 \%$ das mães desejavam um corpo maior para seus filhos e 14\% desejavam corpo mais magro e $39 \%$ estavam satisfeitas com o tamanho corporal de seus filhos.

Podemos observar como a opinião dos pais influencia os filhos quanto a sua imagem corporal. Foram identificadas correlações positivas entre a satisfação dos pais, em relação à imagem corporal dos filhos, e a satisfação da própria criança/adolescente com a sua silhueta $(r=0,496 \mathrm{p}<0,01)$; acurácia da criança/adolescente e a dos seus pais ( $\mathrm{r}=0,309 \mathrm{p}<0,01)$; e correlações positivas entre as perguntas "Como eu acho que a minha mãe/pai gostaria que eu fosse" e "Como eu gostaria de ser" $(r=0,433 \mathrm{p}<0,01)$.

Essa preferência por silhuetas menores por parte dos estudantes, além de ser influenciada pelo ambiente, (pelas normas sociais e pela mídia) que ditam os padrões de beleza, parece ser fortemente influencia pela própria família. Essa insatisfação com a própria imagem corporal, nos jovens pode ser algo perigoso porque tais insatisfações podem desencadear transtornos psicológicos e alimentares no futuro.

Não obtivemos diferenças estatísticas ao analisarmos a relação entre os estilos parentais e a acurácia/satisfação em relação ao tamanho corporal dos estudantes. Também não foi encontrado diferenças estatísticas em relação aos estilos parentais e a acurácia/satisfação dos pais em relação ao tamanho corporal dos filhos. 


\section{CONCLUSÕES}

Observamos que uma pequena parcela dos estudantes tem uma percepção acurada do seu tamanho corporal, o que se correlacionou positivamente com a percepção inacurada dos pais, demonstrando que a percepção dos pais interfere na acurácia da própria criança em relação a sua imagem corporal.

As crianças estão cada vez mais precocemente demonstrando insatisfação com a sua imagem corporal. Esse desejo por uma silhueta menor pode ser influenciado pela própria família, pois a maioria dos pais demonstrou insatisfação com a imagem corporal dos filhos. A forma como a criança acredita que os seus pais gostariam que ela fosse interfere diretamente na forma como ela gostaria de ser e na forma como ela se vê. A figura mais escolhida entre os estudantes como sendo a ideal, tanto para as meninas quanto para os meninos, foi a de número quatro demonstrando o desejo por silhuetas menores igualmente entre os sexos. No presente estudo não foi observada diferença entre meninos e meninas, os meninos demonstraram preferência por silhuetas menores, tanto quanto as meninas.

Os pais têm uma percepção distorcida da imagem corporal dos filhos, demonstrando uma tendência para subestimarem seu verdadeiro estado nutricional, essa distorção é maior quanto mais elevado o IMC. 


\section{CONSIDERAÇÕES FINAIS}

Os resultados obtidos no presente estudo confirmam a preocupante taxa de sobrepeso e obesidade encontrados nas crianças e adolescentes. Os pais precisam ser conscientizados de que são os principais exemplos para os filhos, de que suas atitudes e práticas modelam o comportamento dos filhos e isso se estende para a alimentação e prática de atividade física.

Os meninos demonstraram preferência por silhuetas menores, tanto quanto as meninas. $\mathrm{O}$ que pode indicar mudança nos padrões de beleza para os meninos.

A subestimação do tamanho corporal pode ser um obstáculo para o tratamento nutricional. Conscientizar os pais a reconhecerem o real estado nutricional dos seus filhos e de que o excesso de peso é um problema de saúde e que deve ser tratado o quanto antes, e em conjunto com toda a família pode ser o primeiro passo para a adoção de hábitos mais saudáveis. 


\section{REFERÊNCIAS}

AMERICAN ACADEMY OF PEDIATRICS, Committee on Public Education Children, Adolescents, and Television. Pediatrics. v. 107, p. 423-426, 2001.

ASSOCIACAO BRASILEIRA DE EMPRESAS DE PESQUISA (ABEP). Critério de Classificação Econômica Brasil. 2015. São Paulo. Disponível em: <http://www.abep.org/criterio-brasil>. Acesso em: set. 2015.

APARÍCIO, G.; CUNHA, M.; DUARTE, J.; PEREIRA, A. Olhar dos pais sobre o estado nutricional das crianças pré-escolares. Millennium. v. 40, p. 99-113, 2011.

BAUGHCUM, A. E.; CHAMBERLIN, L.; DEEKS, C. POWERS, S.; WHITAKER R. Maternal perceptions of overweight preschool children. Pediatrics. v. 106 p. 13801386, 2000.

BAUMRIND, D. Effects of authoritative control on child behavior. Child Development. v. 37, p. 887-907, 1966.

BENCHAYA, M. C.; BISCH, N. K.; MOREIRA, T. C.; FERIGOLO, M.; BARROS, H. M. T. Pais não autoritativos e o impacto no uso de drogas: a percepção dos filhos adolescentes. Jornal de Pediatria. v. 87, p. 238-244, 2011.

BIRCH, L. Psychological influences on the childhood diet. Journal of Nutrition. v. 128, p. 407-410, 1998.

BLISSETT, J.; HAYCRAFT, E. Are parenting style and controlling feeding practices related? Appetite. v. 50, p. 477-485, 2008.

CAMARGO, A. P. P. M.; BARROS FILHO, A. A.; ANTONIO, M. A. R. G. M.; GIGLIO. J. S. A não percepção da obesidade pode ser um obstáculo no papel das mães de cuidar de seus filhos. Ciência \& saúde coletiva. v.18, p. 323-333, 2013.

CASH, T. F. Body image: past, present, and future. Body Image.v.1, p. 1-5, 2004.

CHUPROSKI, P.; DE MELLO, D. F. Percepção materna do estado nutricional de seus filhos. Revista de Nutrição, Campinas. v. 22, p. 929-936, 2009.

COCCHETTO, F. H.; PENÃ, D. B.; PELLANDA, L. C. Insatisfação da imagem corporal e estado nutricional em crianças de 7 a 11 anos: estudo transversal. Clinical and Biomedical Research v. 35, p. 86-91, 2015.

COHEN, D. A.; RICE, J. Parenting Style, adolescent substance use, and academic achievement. Journal of Drug Education. v. 27 p. 199-211, 1997.

COSTA, F. T., TEIXEIRA, M. A. P.; GOMES, W. B. Responsividade e exigência: Duas escalas para avaliar estilos parentais. Psicologia: Reflexão e Crítica. v. 13, p. 465-473, 2000.

DARLING, N.; STEINBERG, L. Parentingstyle as context: anintegrativemodel. Psychological Bulletin Journal v. 113, 487-96, 1993.

DUCHIN, O.; MARIN, C.; PLAZAS, M. M.; VILLAMOR, E. Maternal body image dissatisfaction and BMI change in school age children. Public Health Nutrition. v, p. 
$1-6,2015$.

EBBELING, C.; PAWLAK, D.; LUDWIG, D. Childhood obesity: public health crisis, common sense cure. Lancet. v. 360, p. 473-482, 2002.

FONSECA, P. N.; ANDRADE, P. O.; SANTOS, J. L. F.; CUNHA, J. E. M.; ALBUQUERQUE, J. H. A. Hábitos de estudo e estilos parentais: estudo correlacional. ssociação Brasileira de Psicologia Escolar e Educacional. v. 18, p. 337-345, 2014.

GILLESPIE, A.; ACTERBERG, C. Comparison of family interaction patterns related to food and nutrition. Journal of the American Dietetic Association. v.89, p. 509-512, 1989.

GIUGLIANO, R.; CARNEIRO, E. C.; Fatores associados à obesidade em escolares Journal de Pediatria.; v. 80, p. 17-22, 2004.

GUEDES, D. P; MIRANDA, J. T.; ALMEIDA, N. M. J.; SILVA, A. J. R. M. Impacto de fatores sociodemográficos e comportamentais na prevalência de sobrepeso e obesidade de escolares. Revista Brasileira de Cineantropometria e Desempenho Humano. v. 12, p. 221-231, 2010.

IBGE. Pesquisa de Orçamentos Familiares 2008 2009: Antropometria e estado nutricional de crianças, adolescentes e adultos no Brasil. Rio de Janeiro, RJ, 2010. Disponível em: <http://www.ibge.gov.br/home/estatistica/populacao/condicaodevida/po/2008_2009_en caa/pof_20082009_encaa.pdf>. Acesso em: set. 2015.

IBGE. Pesquisa de Orçamentos Familiares 2002 2003: Análise da disponibilidade domiciliar de alimentos e do estado nutricional de no Brasil. Rio de Janeiro, RJ, 2004.

em: < http://189.28.128.100/dab/docs/portaldab/documentos/pof2002analise_nutr.pdf $<$. Acesso em: set. 2015.

JEBB, S.; MOORE, M. Contribution of a sedentary lifestyle and inactivity to the etiology of overweight and obesity: current evidence and research issues. Medicine \& Science in Sports \& Exercise. v. 31, p. 534-541, 1999.

KAKINAMI, L.; BARNETT, T. A.; SEGUIN L. PARADIS G. Parenting style and obesity risk in children. Preventive Medicine. v. 75 p. 18-22, 2015.

KAKESHITA, I. S.; ALMEIDA, S. A. Relação entre índice de massa corporal e a percepção da auto-imagem em universitários. Revista de Saúde Pública. v. 40, p. 497504, 2006.

KAKESHITA, I. S.; SILVA, A. I. P.; ZANATTA, D. P.; ALMEIDA, S. A. Construção e fidedignidade teste-reteste de escalas de silhuetas brasileiras para adultos e crianças. Psicologia: Teoria e Pesquisa. v. 25, p. 263-270, 2009.

KOIVISTO, U.; SJÖDÉN, P. Reasons for rejection of food items in swedish families with children aged 2-17. Appetite. v.26, p. 89-103, 1996.

KORNILAKI, E. N. Obesity bias in children: The role of actual and perceived body size. Infant and Child Development. v. 24, p. 10-24, 2015. 
LAMBORN, S. D.; MOUNTS, N. S.; STEINBERG, L.; DORNBUSCH, S. M. Patterns of competence and adjustment among adolescents from authoritative, authoritarian, indulgent, and neglectful families. Child Development. v. 62, p. 1049-65, 1991.

LELII, S. D. Can I reach that sticker. Preschoolers' practical judgments about their own and others' body size. Jornal Of Cognition and Development. V. 15, p. 584-598, 2015.

LEITE, A. C. B.; FERRAZZI, N. B.; MEZADRI, T. HOFELMANN, D. A. Insatisfação corporal em escolares de uma cidade do sul do Brasil. Journal of Human Growth and Development. v. 24, p. 54-61, 2014.

MACCOBY, E.; MARTIN, J. Socialization in the context of the family: Parent-child interaction. Handbook of child psychology, socialization, personality, and social development. $4^{\text {a }}$ ed. New York: Wiley,. 1983.

MAYER, A. P. F.; WEBER, L. N. D.; BRANDENBURG, TON, T. C.; Perfis parentais com base nas práticas educativas e alimentares: Análise por agrupamento. Psicologia, Saúde \& Doenças. v. 15, p.683-697, 2014.

MELLO, E. D.; LUFT, V. C.; MEYER, F. Obesidade infantil: como podemos ser eficazes? Jornal de Pediatria. v. 80, p.173-82, 2004.

MEIZI, H. M. M.; EVANS, A. Lesparentssont-ilsconscients que leurs enfants souffrent de surpoids ou d'obésité? Canadian Family Physician. v. 53, p. 1493-1499, 2007.

MINISTÉRIO DA SAÚDE. Vigilância Alimentar e Nutricional - SISVAN: Orientações Básicas para a coleta, processamento, análise de dados e informação em Serviços de Saúde. Brasília: Ministério da Saúde, 2004. Disponível em: < http://pfdc.pgr.mpf.gov.br/atuacao-e-conteudos-de-apoio/publicacoes/alimentacaoadequada/orientacoes_basicas_sisvan.pdf>. Acesso em: set. 2015.

MORAES, P. M.; DIAS, C. M. S. B. Nem Só de Pão se Vive: A Voz das Mães na Obesidade Infantil. Psicologia: Ciência e Profissão. v. 33, p. 46-59, 2013.

NEIGHBORS, L. A.; SOBAL, J. Prevalence and magnitude of body weight and shape dissatisfaction among university students. Eating Behaviors. v. 8, p 429-439, 2007.

OLIVEIRA, J. S.; BARUFALDI, L. A.; ABREU, G. A.; LEAL, V.S.; BRUNKEN, G.S.; VASCONCELOS, S. M. L. et al. ERICA: Uso de telas e consume de refeições e petiscos por adolescentes. Revista de Saúde Pública. V. 50, p. 1-8, 2016.

PARKINSON, K. N.; DREWETT, R. F.; JONES, A. R.; ADAMSON, A. J. Mothers' judgements about their child's weight: distinguishing facts from values. Child: Care, Health and Development. v. 39, p. 722-727, 2012.

PECKHAM, P. J. A.; LOPEZ, M. A. A. College drinking behaviors: Mediational links Between parenting styles, impulse control, and alcohol-related outcomes. Psychology Addict Behavior. v. 20 p. 117-25, 2006.

PELEGRINI, A.; COQUEIRO, R. S.; BECK, C. C.; GHEDIN, K. D.; LOPES, A. S.; PETROSKI, E. D. Dissatisfaction with body image among adolescent students: association with socio-demographic factors and nutritional status. Ciência \& Saúde Coletiva. v. 19, p. $1201-1208,2014$. 
PEREIRA, E. F.; GRAUP, S.; LOPES, A. S.; BORGATTO, A. F.; DARONCO, L. S. E.; Percepção da imagem corporal de crianças e adolescents com diferentes níveis socio-economicos na cidade de Florianópolis, Santa Catarina, Brasil. Revista Brasileira de Saúde Materno Infantil. v. 9, p. 253-262, 2009.

POPKIN, B. M.; GUO, X. M. H.; ZOHOORI, N. The nutrition transition in China: A cross sectional analysis. European Journal of Clinical Nutrition. v. 47, p. 333-346, 1993.

PIERINE, D. T.; CARRASCOSA, A. P. M.; FORNAZARI, A. C.; WATANABE, M. T.; CATALANI, M. C. T.; FUKUJU, M. M.; SILVA, G. N.; MAEST, N. Composição corporal, atividade física e consumo alimentar de alunos do ensino fundamental e médio. Motriz, Rio Claro, v.12, p.113-124, 2006.

RIVERA, J. A.; DE COSSÍO, T. G.; PEDRAZA, L. S.; ABURTO, T. C.; SÁNCHEZ, T.G.; MARTORELL, R. Childhood And adolescent overweight and obesity In Latin America: a systematic review. Lancet Diabetes \& Endocrinology. v. 2, p. 321-332, 2014.

SLADE, P. D. What is body image? Behaviour Research Therapy. v. 32, p. 497-502, 1994.

SILVA, O. W. Questionário de avaliação da atividade física e do sedentarismo em crianças e adolescentes. Revista do DERC. v. 45, p. 14-18, 2009.

SMOLAK, L. Body image in children and adolescents: Where do we go from here? Body Image. v. 1, p. 15-28, 2004.

TAVARES, M. C. G. C. F. Imagem Corporal - Conceito e Desenvolvimento. $1^{\text {a }}$ ed. São Paulo; Manolo, 2003.

VIGITEL. Departamento de Análise de Situação de Saúde. Vigilância de Fatores de Risco e Proteção para Doenças Crônicas por Inquérito Telefônico, VIGITEL 2016. Brasília: DF; 2016.

WEBER, L. N. D.; BRANDENBURG, O. J; VIEZZER, A. P. A relação entre o estilo parental e o otimismo da criança. Psico-USF. v. 8, p. 71-79, 2003.

WEBER, L. N. D.; PRADO, P. M.; VIEZZER, A. P.; BRANDENBURG. O. J. Identificação de Estilos Parentais: O Ponto de Vista dos Pais e dos Filhos. Psicologia: Reflexão e Crítica. v. 17, p. 323-331, 2004.

WORLD HEALTH ORGANIZATION (WHO).Physical status: the use and interpretation of anthropometry. Geneva: WHO; 2000. Technical Report Series 854.

WORLD HEALTH ORGANIZATION (WHO). Ministério da Saúde. Curvas de Crescimento para crianças. 2007. Disponível em:

http://189.28.128.100/nutricao/docs/graficos_oms/maiores_5anos/imc_por_idade meni nas_percentis.pdf Acesso em: 05/12/2016.

WORLD HEALTH ORGANIZATION (WHO). Global Status report of non 
communicable

diseases

2010.

Geneva:

WHO;

2011.

WORLD HEALTH ORGANIZATION. Obesity - preventing and managing the global epidemic. Report of a WHO consulation on obesity. Geneva: WHO, 1998.

WORLD HEALTH ORGANIZATION (WHO). World Health Statistics 2015. Geneva: WHO; 2015.

WRIGHT, C.; PARKER, L.; LAMONT, D.; CRAFT, A. Implications of childhood obesity for adult health: findings from thousand families cohort study. British Medical Journal. v. 323 p. 1280-4, 2001. 


\section{Apêndice A \\ TERMO DE CONSENTIMENTO LIVRE E ESCLARECIDO - Pais}

O (a) senhor (a) esta sendo convidado (a) a participar como voluntários (a) de uma pesquisa. Após ser esclarecido (a) sobre as informações a seguir, você poderá escolher entre participar ou não deste estudo. Em caso de recusar a participação você não será penalizados de forma alguma. Caso o (a) senhor (a) tenha interesse em participar da pesquisa, solicitamos que devolva esse termo assinado. Uma via deste consentimento informado será arquivada com o pesquisador responsável e outra será fornecida a você.

Será garantido total sigilo das informações coletadas, que serão utilizadas apenas em publicações em revistas especializadas e em congressos da área. Seu nome ou e suas informações não aparecera em nenhuma dessas publicações. Em caso de dúvida, você pode consultar os pesquisadores responsáveis: Nelly Kim Mayuri Okuda e Prof. Dr. Sebastião de Sousa Almeida.

\section{INFORMAÇÕES SOBRE A PESQUISA:}

Título do Projeto: Influência dos Estilos Parentais no estado nutricional de crianças e adolescentes

\section{Pesquisadores Responsáveis:}

Nelly K. M. Okuda Telefone: (16) 3602-4391 - Laboratório de Nutrição e Comportamento do Departamento de Psicobiologia da FFCLRP - USP.

Prof. Dr. Sebastião de Sousa Almeida. Telefone: (16) 3602-3663

$\mathrm{Na}$ infância, a família é considerada o principal apoio ao indivíduo interferindo no desenvolvimento da criança. É necessário um maior entendimento de como os estilos parentais podem contribuir para o entendimento da influência exercida pelos pais sobre os filhos. $\mathrm{O}$ objetivo desta pesquisa é verificar a influência dos estilos parentais no estado nutricional de crianças e adolescentes. Os resultados desta pesquisa poderão ser de grande utilidade para o estabelecimento de Políticas Públicas de Saúde e adquirir caráter de prevenção de inúmeros problemas de comportamentos e nutricionais o que justifica a realização desta pesquisa.

Ao optar por participar desta pesquisa será necessário que você responda a um questionário sobre os dados socioeconômicos da sua família. Esse questionário está sendo enviado a você juntamente com esse termo e, caso se interesse em participar da pesquisa, pode respondê-lo e enviá-lo juntamente com uma via assinada do termo para a escola. Você deverá responder também a um questionário que será aplicado pela pesquisadora deste projeto em um encontro, que deve durar aproximadamente 30 minutos, e que será respondido após a reunião de pais e mestres (a data deste encontro será confirmada posteriormente). Solicitamos a sua 
colaboração a completar todas as perguntas do roteiro que lhe será solicitado, garantindo assim o melhor resultado para a pesquisa.

A sua participação na pesquisa consite em:

- Preenchimento de questionários sobre a relação entre pais e filhos e imagem corporal.

Você será esclarecido (a) sobre a pesquisa em qualquer aspecto e sempre que desejar, e é livre para recusar ou interromper a participação a qualquer momento.

A sua presença nesta pesquisa é voluntária e a recusa em participar não irá ocasionar qualquer penalidade. A participação no estudo não acarretará nenhum tipo premiação ou reembolso, já que com a sua participação na pesquisa você não terá nenhum gasto.

$\mathrm{Eu}$,

após a leitura deste documento acredito estar suficientemente informado, ficando claro para mim que minha participação é voluntária e que posso retirar este consentimento a qualquer momento sem penalidades ou perda de qualquer benefício. Fui informado (a) dos objetivos do estudo "Influência dos Estilos Parentais no estado nutricional de crianças e adolescentes", e dos procedimentos nele envolvidos, e sei que em caso de dúvidas poderei contatar os pesquisadores responsáveis. Declaro que recebi uma via deste termo de consentimento livre e esclarecido, sendo-me garantido que posso retirar o consentimento de participação a qualquer momento, sem que isto leve a qualquer penalidade.

Assinatura do responsável responsável
Assinatura do pesquisador

Nelly K. M. Okuda

Assinatura do orientador

Prof. Dr. Sebastião de Sousa Almeida

Contato para denúncias e/ou reclamações referentes aos aspectos éticos da pesquisa:

Comitê de Ética em Pesquisa da Faculdade de Filosofia, Ciências e Letras de Ribeirão Preto - USP

Avenida Bandeirantes, 3900 - Bloco 23 - Casa 37 - 14040-901 - Ribeirão Preto - SP - Brasil

Fone: (16) 3602-4811/Fax: (16)3633-2660 (direto) ou 3633-5015

E-mail: coetp@ffclrp.usp.br/ homepage: http://www.ffclrp.usp.br 


\section{Apêndice B \\ TERMO DE CONSENTIMENTO LIVRE E ESCLARECIDO - Crianças}

O (a) seu filho esta sendo convidado (a) a participar como voluntário (a) de uma pesquisa. Após ser esclarecido (a) sobre as informações a seguir, você poderá escolher entre autorizar a participação do seu filho (a) ou não neste estudo. Em caso de recusar a participação o seu filho não será penalizado de forma alguma. Caso o (a) senhor (a) tenha interesse que o seu (sua) filho (a) participe da pesquisa, solicitamos que devolva esse termo assinado. Uma via deste consentimento informado será arquivada com o pesquisador responsável e outra será fornecida a você.

Será garantido total sigilo das informações coletadas, que serão utilizadas apenas em publicações em revistas especializadas e em congressos da área. O nome de seu filho (a) e as informações dele não aparecerá em nenhuma dessas publicações. Em caso de dúvida, você pode consultar os pesquisadores responsáveis: Nelly Kim Mayuri Okuda e Prof. Dr. Sebastião de Sousa Almeida.

\section{INFORMAÇÕES SOBRE A PESQUISA:}

\section{Título do Projeto: Influência dos Estilos Parentais no estado nutricional de crianças e adolescentes}

\section{Pesquisadores Responsáveis:}

Nelly K. M. Okuda Telefone: (16) 3602-4391 - Laboratório de Nutrição e Comportamento do Departamento de Psicobiologia da FFCLRP - USP.

Prof. Dr. Sebastião de Sousa Almeida. Telefone: (16) 3602-3663

A participação de seu filho (a) na pesquisa consiste em:

- Preenchimento de questionários sobre: a relação com os pais e atividade física;

- Responder a perguntas sobre imagem corporal e maturação sexual;

- Ter suas medidas de peso e altura aferidas.

A pesquisa será realizada na escola e não irá prejudicar os conteúdos escolares, os horários de aulas ou impedir seu filho (a) de assisti-las; Os questionários serão respondidos em sala de aula, com duração aproximada de 40 minutos, sob supervisão da pesquisadora responsável. A mesma pesquisadora também será responsável pela pesagem e mensuração da altura, o que será realizado individualmente, em outra sala da escola. 
Solicitamos a colaboração de seu (sua) filho (a) a completar todo o roteiro de perguntas que lhe será solicitado, garantindo assim o melhor resultado para a pesquisa.

A presença do seu filho (a) nesta pesquisa é voluntária e a recusa em participar não irá ocasionar qualquer penalidade. A participação no estudo não acarretará nenhum tipo premiação ou reembolso, já que com a participação de seu filho (a) na pesquisa você não terá nenhum gasto.

$\mathrm{Eu}$,

responsável pelo (a) menor

autorizo a participação do meu filho no estudo "Influência dos Estilos Parentais no estado nutricional de crianças e adolescentes". Fui informado (a) dos objetivos do estudo acima e os procedimentos nele envolvidos, e sei que em caso de dúvidas poderei contatar os pesquisadores responsáveis. Declaro que recebi uma cópia deste termo de consentimento livre e esclarecido, sendo-me garantido que posso retirar o consentimento de participação a qualquer momento, sem que isto leve a qualquer penalidade.

Assinatura do participante

Assinatura do pesquisador

Assinatura do orientador

Prof. Dr. Sebastião de Sousa Almeida

Contato para denúncias e/ou reclamações referentes aos aspectos éticos da pesquisa:

Comitê de Ética em Pesquisa da Faculdade de Filosofia, Ciências e Letras de Ribeirão Preto - USP Avenida Bandeirantes, 3900 - Bloco 23 - Casa 37 - 14040-901 - Ribeirão Preto - SP - Brasil

Fone: (16) 3602-4811/Fax: (16)3633-2660 (direto) ou 3633-5015

E-mail: coetp@ @ffclrp.usp.br/ homepage: http://www.ffclrp.usp.br 


\section{Apêndice C}

\section{Termo de Assentimento - Adolescentes de 12 anos}

Você está sendo convidado(a) como voluntário(a) a participar da pesquisa "Influência dos Estilos Parentais no estado nutricional de crianças e adolescentes". Neste estudo pretendemos verificar a influência da relação entre pais e filhos no estado nutricional de crianças e adolescentes. Os resultados desta pesquisa poderão ser de grande importância na prevenção de inúmeros problemas de comportamento e nutricionais.

\section{Pesquisadores Responsáveis:}

Nelly K. M. Okuda. Telefone: (16) 3602-4391 - Laboratório de Nutrição e Comportamento do Departamento de Psicobiologia da FFCLRP - USP.

Prof. Dr. Sebastião de Sousa Almeida. Telefone: (16) 3602-3663

A sua participação na pesquisa consiste em:

- Preenchimento de questionários sobre: a relação com os pais e atividade física;

- Responder a perguntas sobre imagem corporal e maturação sexual;

- Ter suas medidas de peso e altura aferidas.

A pesquisa será realizada na escola e não irá prejudicar os conteúdos escolares e os horários de aulas. Os questionários serão respondidos em sala de aula, com duração aproximada de 40 minutos, sob supervisão da pesquisadora responsável. A mesma pesquisadora também será responsável pela pesagem e mensuração da altura, o que será realizado individualmente, em outra sala da escola. Solicitamos a sua colaboração em completar todo o roteiro de perguntas que lhe será solicitado, garantindo assim o melhor resultado para a pesquisa.

Para participar deste estudo, o responsável por você deverá autorizar e assinar um termo de consentimento. Você não terá nenhum custo, nem receberá qualquer vantagem financeira. Você será esclarecido(a) em qualquer aspecto que desejar e estará livre para participar ou recusar-se. O responsável por você poderá retirar o consentimento ou interromper a sua participação a qualquer momento. A sua participação é voluntária e a recusa em participar não acarretará 
qualquer penalidade. Você não será identificado em nenhuma publicação. Este termo de consentimento encontra-se impresso em duas vias, sendo que uma cópia será arquivada pelo pesquisador responsável, e a outra será fornecida a você.

$\mathrm{Eu}$,

fui informado(a) dos objetivos do presente estudo de maneira clara. Sei que a qualquer momento poderei solicitar novas informações junto ao pesquisador responsável ou com o acadêmico. Estou ciente que o meu responsável poderá modificar a decisão da minha participação na pesquisa, se assim desejar. Tendo o consentimento do meu responsável já assinado, declaro que concordo em participar desse estudo. Recebi uma cópia deste termo assentimento e me foi dada a oportunidade de ler e esclarecer as minhas dúvidas

Assinatura do responsável

Assinatura do menor

Assinatura do orientador

Assinatura da pesquisadora

Prof. Dr. Sebastião de Sousa Almeida

Nelly K. M. Okuda

Contato para denúncias e/ou reclamações referentes aos aspectos éticos da pesquisa:

Comitê de Ética em Pesquisa da Faculdade de Filosofia, Ciências e Letras de Ribeirão Preto - USP

Avenida Bandeirantes, 3900 - Bloco 23 - Casa 37 - 14040-901 - Ribeirão Preto - SP - Brasil

Fone: (16) 3602-4811/Fax: (16)3633-2660 (direto) ou 3633-5015

E-mail: coetp@ffclrp.usp.br/ homepage: http://www.ffclrp.usp.br 


\section{Apêndice D}

\section{Questionário de identificação da criança}

Caro (a) aluno (a): A sua ajuda é muito importante para a nossa pesquisa, mas lembramos que você só participa se você quiser. Pedimos que você responda sinceramente todas as questões, sem deixar nenhuma em branco. Não existem respostas certas ou erradas! Caso você marque uma alternativa e deseje mudar, faça um círculo nesta alternativa, e marque com um $\mathrm{X}$ a sua resposta. Ninguém saberá suas respostas. $\mathrm{O}$ resultado é feito em grupos e não individualmente. Muito obrigada pela sua colaboração!

Nome:

1. Idade:

2. Data de Nascimento:

3. Sexo: Masculino Feminino

4.Quantas pessoas moram na sua casa?

7. Quem são?
a) Pai
b) Mãe
c) Avós
d) Irmãos
e) Outros

8. Quantos irmãos você tem?
a) 1
b) 2
c) 3
d) 4
e) 5
f) 6 ou mais
g) Sou filho único

9. Seus pais são:
a) Casados
b) Separados
c) Falecidos
d) Pai falecido
e) Mãe falecida
f) Mãe solteira
g) pai solteiro

10. Se separados ou falecidos, casaram novamente? a) Sim

b) Não 


\section{Anexo A}

Escalas de Exigência e Responsividade

\section{Nome:}

RESPONDA SOBRE SEU PAI E SUA MÃE (OU SOBRE AS PESSOAS POR QUEM FOI EDUCADO, POR EXEMPLO: MADRASTA, PADRASTO, AVÔ, AVÓ, TIO, TIA E OUTROS).

1. Até que ponto seu pai/mãe TENTA saber aonde você vai quando sai com seus amigos?

Pai ( )não tenta ( )tenta pouco ( )tenta bastante Mãe ( )não tenta ( )tenta pouco ( )tenta bastante

2. Até que ponto seu pai/mãe TENTA saber o que você faz com teu tempo livre?

Pai ( )não tenta ( )tenta pouco ( )tenta bastante

Mãe ( )não tenta ( )tenta pouco ( )tenta bastante

3. Até que ponto seu pai/mãe TENTA saber onde você está quando não está na escola?

Pai ( )não tenta ( )tenta pouco ( )tenta bastante

Mãe ( )não tenta ( )tenta pouco ( )tenta bastante

4. Até que ponto seu pai/mãe REALMENTE sabe aonde você vai quando sai com seus amigos?

Pai ( )não sabe ( )sabe pouco ( )sabe bastante

Mãe ( )não sabe ( ) sabe pouco ( )sabe bastante

5. Até que ponto seu pai/mãe REALMENTE sabe o que você faz com seu tempo livre?

Pai ( )não sabe ( )sabe pouco ( )sabe bastante

Mãe ( )não sabe ( )sabe pouco ( )sabe bastante

6. Até que ponto seu pai/mãe REALMENTE sabe onde você esta quando não está na escola?

Pai ( )não sabe ( )sabe pouco ( )sabe bastante

Mãe ( )não sabe ( )sabe pouco ( )sabe bastante

7. Posso contar com a ajuda de meu pai/mãe caso eu tenha algum tipo de problema.

Pai ( )quase nunca ( )às vezes ( )geralmente

Mãe ( )quase nunca ( )às vezes ( )geralmente

8. Ele/Ela me incentiva (anima) a dar o melhor de mim em qualquer coisa que eu faça.

Pai ( )quase nunca ( )às vezes ( )geralmente

Mãe ( )quase nunca ( )às vezes ( )geralmente 
9. Ele/Ela incentiva minhas próprias opiniões.

Pai ( )quase nunca ( )às vezes ( )geralmente

Mãe ( )quase nunca ( )às vezes ( )geralmente

10. Ele/Ela me ajuda nos trabalhos da escola se tem alguma coisa que eu não entendo.

Pai ( )quase nunca ( )às vezes ( )geralmente

Mãe ( )quase nunca ( )às vezes ( )geralmente

11. Quando quer que eu faça alguma coisa, explica-me o porquê.

Pai ( )quase nunca ( )às vezes ( )geralmente

Mãe ( )quase nunca ( )às vezes ( )geralmente

12. Quando você tira uma boa nota na escola, quanto seu pai/mãe elogia você?

Pai ( )quase nunca ( )às vezes ( )geralmente

Mãe ( )quase nunca ( )às vezes ( )geralmente

13. Quando você tira uma nota baixa na escola, quanto seu pai/mãe encoraja você a esforçar-se mais?

Pai ( )quase nunca ( )às vezes ( )geralmente

Mãe ( )quase nunca ( )às vezes ( )geralmente

14. Quantas vezes seu pai/mãe passa um tempo conversando com você?

Pai ( )quase nunca ( )às vezes ( )geralmente

Mãe ( )quase nunca ( )às vezes ( )geralmente

15. Seu pai/mãe realmente sabe quem são seus amigos?

Pai ( )quase nunca ( )às vezes ( )geralmente

Mãe ( )quase nunca ( )às vezes ( )geralmente

16. Quantas vezes você e seu pai/mãe se reúnem para fazerem juntos alguma coisa legal?

Pai ( )quase nunca ( )às vezes ( )geralmente

Mãe ( )quase nunca ( )às vezes ( )geralmente 


\section{Anexo B}

\section{Questionário para Avaliar as Atividades Físicas de Crianças e Adolescentes}

Nome:

Sexo: ( ) M ( ) FIdade: anos Série:

Para responder a estas perguntas você vai procurar se lembrar das atividades físicas ou horas sem fazer atividade física no último mês:

1.DESLOCAMENTO PARA A ESCOLA:( ) não vai ( ) andando ( ) bicicleta ( ) carro / outro transporte

Se você vai andando, de bicicleta ou outro meio que gaste energia (patins, etc), quanto tempo gasta por dia somando ida e volta? minutos por dia vezes por semana

\section{AULAS DE EDUCAÇÃO FÍSICA NA ESCOLA:}

( ) não faz ( ) 1 vez por semana ( ) 2 vezes por semana ( ) 3 vezes por semana

tempo gasto fazendo exercícios: minutos por dia minutos por semana

\section{OUTRAS ATIVIDADES FÍSICAS:}

A) Faz atividades físicas regulares ou esportes?

( ) nunca ou quase nunca ( ) algumas vezes ( ) sempre

B) Pratica atividade física intensa - que o deixa cansado, com a respiração difícil ou o coração acelerado (correr, bicicleta, natação, algum esporte - descreva):

Tipo de exercício: minutos por dia vezes por semana

Tipo de exercício: minutos por dia vezes por semana

Tipo de exercício: minutos por dia vezes por semana

TOTAL: minutos por dia vezes por semana

C) Pratica atividade física leve - que não o deixa muito cansado, nem com a respiração difícil ou o coração muito acelerado (caminhar, outras atividades - descreva):

Tipo de exercício: minutos por dia vezes por semana 
Tipo de exercício: minutos por dia vezes por semana minutos por dia vezes por

Tipo de exercício: semanaTOTAL: minutos por dia vezes por semana

\section{PERÍODOS SEM FAZER ATIVIDADE FÍSICA:}

(descreva o tempo que passa assistindo televisão, vídeo, dvd, no computador, videogame ou ao telefone)

Assistindo tv, vídeo ou dvd: minutos por dia vezes por semana

Jogando no computador ou videogame: minutos por dia vezes por semana

Conversando ao telefone: minutos por dia vezes por semana

total: minutos por dia vezes por semana 


\section{Apêndice E}

\section{Questionário de Identificação do Responsável}

Caros (as) Responsáveis: A sua ajuda é muito importante para a nossa pesquisa, mas lembramos que você só participa se você quiser. Pedimos que você responda sinceramente todas as questões, sem deixar nenhuma em branco. Não existem respostas certas ou erradas! Caso você marque uma alternativa e deseje mudar, faça um círculo nesta alternativa, e marque com um $\mathrm{X}$ a sua resposta. Ninguém saberá suas respostas. $\mathrm{O}$ resultado é feito em grupos e não individualmente. Muito obrigada pela sua colaboraç

Nome:

Idade:

Responsável pelo aluno:

Idade:

1. Grau de parentesco do informante:

2. Qual sua formação escolar ou até que ano estudou?

Qual sua profissão?

Qual é a sua altura? Qual é o seu peso?

Estado civil: Numero de filhos 


\section{Anexo C}

\section{Escalas de Exigência e Responsividade - Pais}

\section{Nome:}

Qual é o grau de parentesco com a criança?

1. Até que ponto você tenta saber aonde o seu filho vai quando sai com os amigos?

( )não tenta ( )tenta pouco ( )tenta bastante

2. Até que ponto você tenta saber o que o seu filho faz no tempo livre?

( )não tenta ( )tenta pouco ( )tenta bastante

3. Até que ponto você tenta saber onde seu filho está quando não está na escola?

( )não tenta ( )tenta pouco ( )tenta bastante

4. Até que ponto você realmente sabe aonde seu filho vai quando sai os amigos?

( )não sabe ( )sabe pouco ( )sabe bastante

5. Até que ponto você realmente sabe o que o seu filho faz no tempo livre?

( )não sabe ( )sabe pouco ( )sabe bastante

6. Até que ponto você realmente sabe onde seu filho esta quando não está na escola?

( )não sabe ( )sabe pouco ( )sabe bastante

7. Seu filho pode contar com a sua ajuda caso tenha algum tipo de problema.

( )quase nunca ( )às vezes ( )geralmente

8. Você o incentiva (anima) a dar o melhor de si em qualquer coisa que ele faça.

( )quase nunca ( )às vezes ( )geralmente 
9. Você o incentiva ter suas próprias opiniões.

( )quase nunca ( )às vezes ( )geralmente

10. Você o ajuda nos trabalhos da escola quando ele apresenta alguma dificuldade.

( )quase nunca ( )às vezes ( )geralmente

11. Quando você quer que ele faça alguma coisa, explica o porquê.

( )quase nunca ( )às vezes ( )geralmente

12. Você o elogia quando tira uma boa nota na escola?

( )quase nunca ( )às vezes ( )geralmente

13. Você o encoraja a esforçar-se mais quando ele tira uma nota baixa na escola?

( )quase nunca ( )às vezes ( )geralmente

14. Quantas vezes você passa um tempo conversando com ele?

( )quase nunca ( )às vezes ( )geralmente

15.Voce realmente sabe quem são seus amigos?

( )quase nunca ( )às vezes ( )geralmente

16. Quantas vezes vocês se reúnem para fazerem juntos alguma coisa legal?

( )quase nunca ( )às vezes ( )geralmente 


\section{Anexo D}

\section{Critério de Classificação Econômica Brasil (CCEB)}

Instruções: Por favor, preencha a opção abaixo de acordo com o grau de instrução do chefe da família. Considere como chefe da família a pessoa que contribui com a maior parte da renda do domicílio.

\begin{tabular}{|l|l|l|}
\hline Grau de instrução do chefe de família & \multicolumn{2}{l|}{} \\
\hline Nomenclatura atual & Nomenclatura anterior \\
\hline Analfabeto / Fundamental I Incompleto & Analfabeto/Primário Incompleto & $(\quad)$ \\
\hline $\begin{array}{l}\text { Fundamental ICompleto / Fundamental II } \\
\text { Incompleto }\end{array}$ & Primário Completo/ Ginásio Incompleto & $(\quad)$ \\
\hline Fundamental Completo/ Médio Incompleto & Ginásio Completo/ Colegial Incompleto & $(\quad)$ \\
\hline Médio Completo/ Superior Incompleto & Colegial Completo/ Superior Incompleto & $(\quad$ ) \\
\hline Superior Completo & Superior Completo & $(\quad)$ \\
\hline
\end{tabular}

Por favor, preencha as questões abaixo com um "X" sobre os itens do seu domicílio, para efeito de classificação econômica. Todos os itens eletrônicos citados devem estar funcionando, incluindo os que estão guardados. Caso não estejam funcionando, considere apenas se tiver intenção de consertar ou repor nos próximos seis meses.

\begin{tabular}{|c|c|c|c|c|c|}
\hline \multicolumn{6}{|l|}{ Quantidade de Itens } \\
\hline Itens de conforto & $\begin{array}{c}\text { Não } \\
\text { possu } \\
\text { i }\end{array}$ & 1 & 2 & 3 & $4+$ \\
\hline \multicolumn{6}{|l|}{ Quantidade de automóveis de passeio exclusivamente para uso particular } \\
\hline \multicolumn{6}{|l|}{$\begin{array}{l}\text { Quantidade de empregados mensalistas, considerando apenas osque } \\
\text { trabalham pelo menos cinco dias por semana }\end{array}$} \\
\hline \multicolumn{6}{|l|}{ Quantidade de máquinas de lavar roupa, excluindo tanquinho } \\
\hline \multicolumn{6}{|l|}{ Quantidade de banheiros } \\
\hline \multicolumn{6}{|l|}{$\begin{array}{l}\text { DVD, incluindo qualquer dispositivo que leia DVD e } \\
\text { desconsiderandoDVD de automóvel }\end{array}$} \\
\hline \multicolumn{6}{|l|}{ Quantidade de geladeiras } \\
\hline \multicolumn{6}{|l|}{ Quantidade de freezers independentes ou parte da geladeira duplex } \\
\hline \multicolumn{6}{|l|}{$\begin{array}{l}\text { Quantidade de microcomputadores, considerando computadores demesa, } \\
\text { laptops, notebooks e netbooks e desconsiderando tablets,palms ou } \\
\text { smartphones }\end{array}$} \\
\hline \multicolumn{6}{|l|}{ Quantidade de lavadora de louças } \\
\hline \multicolumn{6}{|l|}{ Quantidade de fornos de micro-ondas } \\
\hline \multicolumn{6}{|l|}{$\begin{array}{l}\text { Quantidade de motocicletas, desconsiderando as usadasexclusivamente } \\
\text { para uso profissional }\end{array}$} \\
\hline Quantidade de máquinas secadoras de roupas, considerando lava eseca & & & & & \\
\hline
\end{tabular}

A água utilizada em seu domicílio é proveniente de?
( ) Rede geral de distribuição ( ) Poço ou nascente ( ) Outro meio Considerando o trecho da rua do seu domicílio, você diria que a rua é:
( ) Asfaltada/ Pavimentada
( ) Terra/ Cascalho 
Anexo E

Escala de Figuras de Silhuetas Infantil
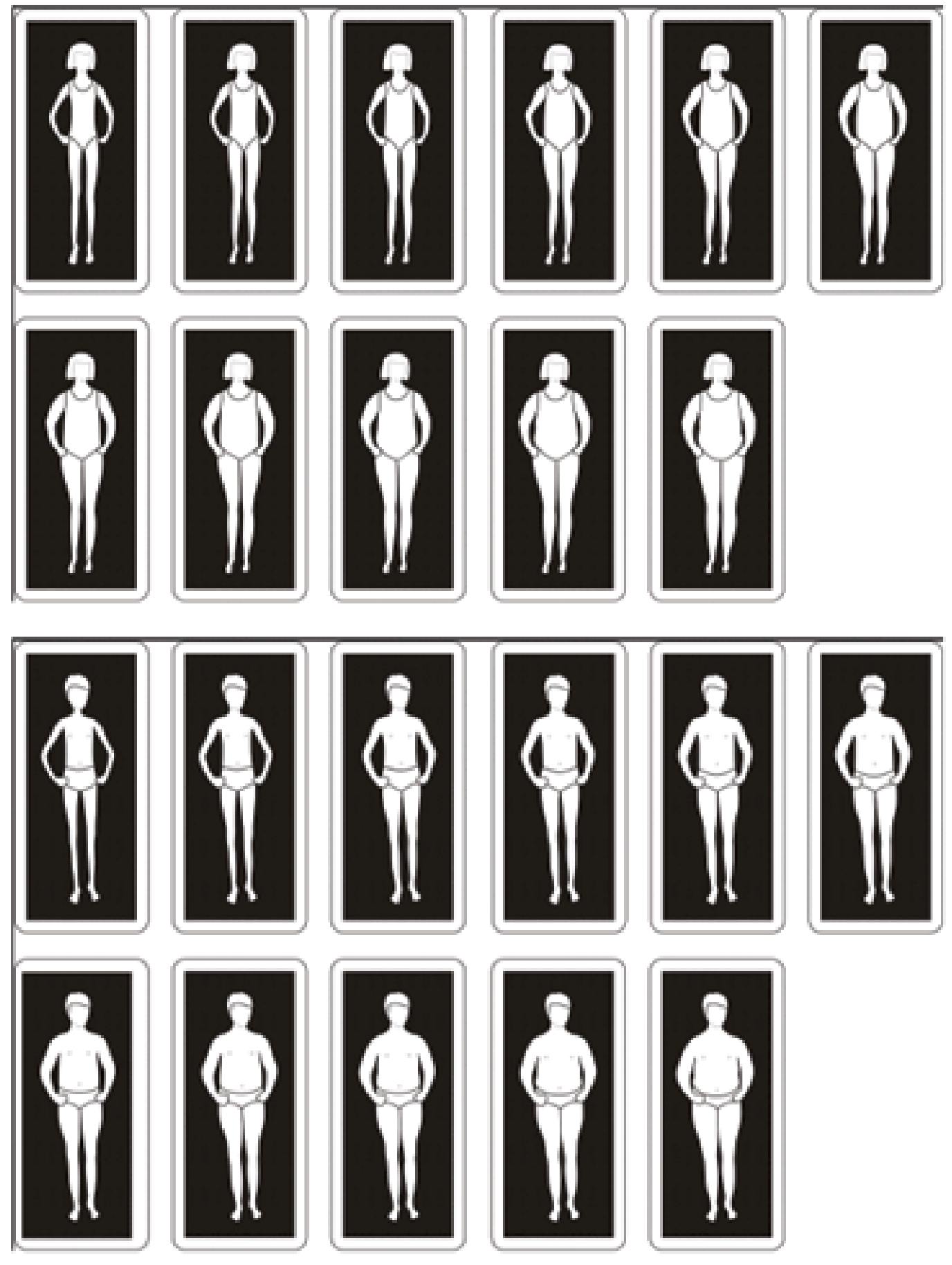